Article

\title{
Combination Effect of Baffle Arrangement and Hybrid Nanofluid on Thermal Performance of a Shell and Tube Heat Exchanger Using 3-D Homogeneous Mixture Model
}

\author{
Mashhour A. Alazwari ${ }^{1}$ (D) and Mohammad Reza Safaei 1,2,3,*(D) \\ 1 Mechanical Engineering Department, Faculty of Engineering, King Abdulaziz University, Jeddah 21589, \\ Saudi Arabia; maalazwari@kau.edu.sa \\ 2 Department of Medical Research, China Medical University Hospital, China Medical University, \\ Taichung 40402, Taiwan \\ 3 Department of Civil and Environmental Engineering, Florida International University, Miami, FL 33174, USA \\ * Correspondence: msafaei@fiu.edu; Tel.: +1-502-657-9981
}

check for

updates

Citation: Alazwari, M.A.; Safaei, M.R. Combination Effect of Baffle Arrangement and Hybrid Nanofluid on Thermal Performance of a Shell and Tube Heat Exchanger Using 3-D Homogeneous Mixture Model. Mathematics 2021, 9, 881. https:// doi.org/10.3390/math9080881

Academic Editors: Mariano Torrisi and Arturo Hidalgo

Received: 21 February 2021

Accepted: 13 April 2021

Published: 16 April 2021

Publisher's Note: MDPI stays neutral with regard to jurisdictional claims in published maps and institutional affiliations.

Copyright: (c) 2021 by the authors. Licensee MDPI, Basel, Switzerland. This article is an open access article distributed under the terms and conditions of the Creative Commons Attribution (CC BY) license (https:/ / creativecommons.org/licenses/by/ $4.0 /)$.

\begin{abstract}
In this study, thermal performance and flow characteristics of a shell and tube heat exchanger equipped with various baffle angles were studied. The heat exchanger was operated with distilled water, and a hybrid nanofluid at three concentrations of $0.04 \%$ and $0.10 \%$ of GNP-Ag/water within Reynolds numbers ranged between 10,000 and 20,000. The thermophysical properties of nanofluid varied with temperature and nanoparticles' concentration. The baffle angles were set at $45^{\circ}, 90^{\circ}, 135^{\circ}$, and $180^{\circ}$. Results showed that the calculated Nusselt number $(\mathrm{Nu})$ could be improved by adding nanoparticles to the distilled water or increasing the fluid's Reynolds number. At a low Re number, the $\mathrm{Nu}$ corresponding to baffle angle of $135^{\circ}$ was very close to that recorded for the angle of $180^{\circ}$. At $\operatorname{Re}=20,000$, the Nu number was the highest (by 35\% compared to the reference case), belonging to a baffle angle of $135^{\circ}$. Additionally, results related to friction factor and pressure drop showed that more locations with fluid blocking were observed by increasing the baffle angle, resulting in increased pressure drop value and friction. Finally, the temperature streamlines counter showed that the best baffle angle could be $135^{\circ}$ in which maximum heat removal and the best thermal performance can be observed.
\end{abstract}

Keywords: shell and tube heat exchanger; hybrid nanofluid; mixture model; variable thermophysical properties; 3-D modeling; baffle angle

\section{Introduction}

With significant progress in thermal engineering systems and modernization and empowerment of chemical and thermal processes, there is an ongoing effort to develop new technologies and techniques to improve heat transfer. Since large heat flux applications need special solutions/arrangements, extensive studies have been performed to improve the systems' thermal performance by new heat removal methods [1]. It has been demonstrated that nano-suspensions can promote the systems' performance by increasing the working fluid's thermal conductivity and enhancing flow characteristics. Hence, systems become more resilient against high heat flux conditions [2,3]. Formerly, studies were primarily focused on suspensions containing microparticles with a mean size of millimeters or micrometer. Despite successful demonstration and case studies, one major problem of using microparticles was the formation of particle sedimentation in liquid, which decreased the system's performance by inducing thermal resistance in the system [4,5]. Since the introduction of nano-suspensions and nanofluids by Choi, in 1995 [6], much effort has been made to commercialize and industrialize the nanofluids without stability problems and sedimentation formation. It has been found that the physics of the heat exchanger and also the pressure drop associated with the flow channels can be critical parameters in such systems $[7,8]$. 
As mentioned, higher thermal conductivity, compared to the common working fluids like water, oil, etc., due to nanoparticles' use is the foremost essential characteristic of nanofluids [9]. Accordingly, nanofluids become an attractive heat transfer fluid for some practical applications. For example, recently, nanofluid's heat transfer study through a heat tube system i.e., microchannel, heat exchanger, and PVT panel, has attracted significant attention by researchers attention $[10,11]$. In a series of tests conducted by various researchers, different nanofluids were tested, and it was demonstrated that the heat transfer of the system could be improved once nanoparticles are in the system, which was due to the Brownian motion, thermophoresis effect and also the local agitation to due to the movement of particles [12]. For example, Ambreen and Kim [13] modeled a microchannel operating with two different nanofluids containing $\mathrm{Al}_{2} \mathrm{O}_{3}$ and $\mathrm{TiO}_{2}$ nanoparticles. The models include steady-state flow conditions, assuming that nanofluids are incompressible and have a Newtonian behavior. They found that thermal resistance and temperature gradient reduces by utilizing nanofluids, as the higher the concentration, the lower the thermal resistance. Additionally, those nanofluids containing smaller diameter nanoparticles showed lower thermal resistance. In another study, the $\mathrm{CuO} /$ nanofluid effects on the heated tube's thermal performance was experimented with by Abdollahi-Moghaddam et al. [14]. They prepared nanofluids with concentrations up to 0.7 vol. $\%$ and tested the nanofluids at Reynolds numbers of 6200 to 14,200. The observations showed that the heat transfer coefficient increased by $280 \%$. They showed that using 0.7 vol. $\%$ nanofluids can reduce fluid consumption by $37 \%$, which reduced the heat exchanger's size by $55 \%$.

In a numerical study, FMWCNT/ $\mathrm{H}_{2} \mathrm{O}$ nanofluid in a backward-facing contracting channel was investigated by Alrashed et al. [15]. The results showed that by adding nanomaterials to the working fluid, the average friction coefficient did not change much. It was a $\sim 3 \%$ increment in average friction coefficient for each Reynolds number case. Togun et al. [16] studied ducts with double forward-facing steps by taking into account two nanofluids as working fluids containing $\mathrm{CuO}$ and $\mathrm{Al}_{2} \mathrm{O}_{3}$ nanoparticles. They found that Nusselt number is affected by nanoparticle volume fraction and nanofluid velocity. The highest heat transfer was belonging to nanofluid prepared by 4 vol.\% concentration of $\mathrm{Al}_{2} \mathrm{O}_{3}$ nanoparticles. Since there are extensive works conducted on the nanofluids' thermal performance, some of the other studies are summarized in Table 1.

Table 1. Nanofluid heat transfer performance in heat pipe systems.

\begin{tabular}{|c|c|c|c|c|c|}
\hline Authors' Names & Type of Study & $\begin{array}{c}\text { Type of Studied } \\
\text { System }\end{array}$ & Type of Nanofluid & $\begin{array}{c}\text { The Concentration } \\
\text { of Nanofluid }(\%)\end{array}$ & Achievements \\
\hline Ho et al. [17] & $\begin{array}{c}\text { Experimental and } \\
\text { Numerical }\end{array}$ & Circular pipe & $\mathrm{Al}_{2} \mathrm{O}_{3} /$ water & 0-10 vol.\% & $\begin{array}{c}\text { Maximum heat transfer } \\
\text { effectiveness ratio: } \\
1.105 \\
\text { Maximum profit index: } \\
1.065\end{array}$ \\
\hline $\begin{array}{l}\text { Akbarzadeh } \\
\text { Hamedani } \\
\text { et al. [18] }\end{array}$ & Numerical & $\begin{array}{l}\text { Convergent- } \\
\text { divergent } \\
\text { tube }\end{array}$ & $\begin{array}{c}\mathrm{CuO} / \text { water } \\
\mathrm{Al}_{2} \mathrm{O}_{3} / \text { water }\end{array}$ & $0-5$ vol. $\%$ & $\begin{array}{c}\text { Highest } \\
\text { thermal performance: } \\
9.29 \% \text { improvement for } \\
\mathrm{Al}_{2} \mathrm{O}_{3} / \mathrm{H}_{2} \mathrm{O} \text {, compared } \\
\text { to pure water }\end{array}$ \\
\hline $\begin{array}{l}\text { Chaurasia, and } \\
\text { Sarviya [19] }\end{array}$ & $\begin{array}{l}\text { Numerical and } \\
\text { Experimental }\end{array}$ & $\begin{array}{l}\text { Pipe with helical } \\
\text { screw tape insert }\end{array}$ & $\begin{array}{l}\mathrm{CuO} / \text { water } \\
\text { Paraffin wax }\end{array}$ & $0.5 \mathrm{vol} \%$ & $\begin{array}{l}\text { Improvement of } \\
\text { Nusselt number: } 170 \% \\
\text { and } 182 \% \text { for } \\
\text { single and double strip } \\
\text { helical screw tape }\end{array}$ \\
\hline Togun et al. [20] & $\begin{array}{c}\text { Experimental and } \\
\text { Numerical }\end{array}$ & Annular pipe & $\begin{array}{l}\text { Water-based } \mathrm{Al}_{2} \mathrm{O}_{3} \\
\mathrm{TiO}_{2}, \mathrm{CuO}\end{array}$ & $0-2$ vol. $\%$ & $\begin{array}{l}\text { Highest heat transfer } \\
\text { augmentation: } 45.2 \% \\
\left(\mathrm{TiO}_{2}\right), 47.3 \%(\mathrm{CuO}), \\
\text { and } 49 \%\left(\mathrm{Al}_{2} \mathrm{O}_{3}\right) .\end{array}$ \\
\hline
\end{tabular}


Table 1. Cont.

\begin{tabular}{|c|c|c|c|c|c|}
\hline Authors' Names & Type of Study & $\begin{array}{l}\text { Type of Studied } \\
\text { System }\end{array}$ & Type of Nanofluid & $\begin{array}{l}\text { The Concentration } \\
\text { of Nanofluid }(\%)\end{array}$ & Achievements \\
\hline Bahiraei et al. [21] & Numerical & $\begin{array}{l}\text { Rectangular } \\
\text { microchannel }\end{array}$ & $\begin{array}{c}\text { Graphene } \\
\text { nanoplatelets- } \\
\text { silver/water }\end{array}$ & 0-0.1 vol. \% & $\begin{array}{c}\text { Maximum } 17 \% \\
\text { enhancement of } \\
\text { convective heat } \\
\text { transfer coefficient }\end{array}$ \\
\hline $\begin{array}{l}\text { Bagherzadeh } \\
\text { et al. [22] }\end{array}$ & Numerical & $\begin{array}{l}\text { Rectangular } \\
\text { microchannel }\end{array}$ & $\mathrm{Al}_{2} \mathrm{O}_{3} /$ water & $0-6$ vol. $\%$ & $\begin{array}{c}\text { Less than } 2 \% \text { axial } \\
\text { dimensionless velocity } \\
\text { difference, for various } \\
\text { Hartmann numbers, } \\
\text { but the same } \varphi \text { and Re. }\end{array}$ \\
\hline Ting et al. [23] & Analytical & $\begin{array}{l}\text { Parallel Plates } \\
\text { microchannel }\end{array}$ & $\mathrm{Al}_{2} \mathrm{O}_{3} /$ water & $0-4$ vol. $\%$ & $\begin{array}{l}\text { 47\% maximum heat } \\
\text { transfer enhancement }\end{array}$ \\
\hline Goodarzi et al. [24] & Numerical & Microtube & $\mathrm{CuO} / \mathrm{CMC}$ & $0-1.5$ vol. $\%$ & $\begin{array}{l}\sim 51 \% \text { maximum } \\
\text { increment in } \\
\text { Nusselt number }\end{array}$ \\
\hline
\end{tabular}

Regardless of their type and size, heat exchangers play a vital role in an industrial plant. Thereby optimizing their size and efficiency can significantly affect the total power consumption and production improvement. Shell and tube heat exchangers have broad applications in low and high temperatures; thus, they are a point of attraction for further study and development. Heat transfer efficiency, geometry miniaturization, optimization, and hydraulic improvement are some of the hot-debated topics considered by researchers aiming at improving the overall performance of the heat exchanger units, mainly when nanofluids are utilized as the working fluid [25]. For example, Rahimi et al. [26] numerically examined $\mathrm{Al}_{2} \mathrm{O}_{3} /$ water-EG nanofluid turbulent flow within a D-shaped heat exchanger. Nanofluid with 1 vol.\% concentration showed the highest performance and the most significant heat transfer coefficient and friction factor. They used thermal conductivity and viscosity correlations in modeling that derived from their experimental data. Sahu and Dewangan [27] modeled a shell and tube heat exchanger in which $\mathrm{TiO}_{2} /$ water was used as working fluid. They found that the highest nanoparticle volume fraction $(2 \%)$ represented the best thermal performance.

Baffle optimization is a plausible technique and a cost-effective way to alter heat transfer and hydrodynamic in heat exchangers. Gay et al. [28] analyzed the influence of placing a plane in the same direction with baffle cut for better fluid flow distribution. A helical baffle is an example of a transfigured baffle for heat transfer enhancement. Some researchers claim that baffles have the ability to reduce pressure drop through the shell side [29,30]. Petinrin and Dare [31] experimentally examined the effect of convex cut of baffles on hydrodynamic performance of heat exchanger operating with water. They studied the heat exchanger while engine oil and air were also considered as the working fluid. It was observed that heat transfer coefficients and pressure drop value of the heat exchanger with segmental baffles are higher than that of convex-cut baffles. The results also indicated that the convex cut of $45 \%$ had lower thermal performance compared to $30 \%$. Cucumo et al. [32] studied the hydrodynamic characteristics of two heat exchangers with helical baffles. They found that a helical tilt angle of $40^{\circ}$ causes $9 \%$ thermal performance enhancement. Accordingly, higher angles were not recommended. Additionally, the calculated pressure drop was significantly lower than that of calculated for traditional baffles.

In light of the above literature, investigating the baffles in heat exchangers can help obtain better thermal unit performance. However, to the best of the authors' knowledge, changing the baffle angle of heat exchangers needs further investigation, and hence, there is room for further studies in this area. Thus, in this study, heat transfer and fluid specifications of hybrid nanofluid flow through a shell and tube heat exchanger were numerically studied by focusing on the baffle arrangement. Four types of baffle arrangements were considered with changing in baffle angles, including $45^{\circ}, 90^{\circ}, 135^{\circ}$, and $180^{\circ}$. The modeling 
was validated against the data published in the literature. The model provides Nusselt number, friction factor, and pressure drop characteristics for distilled water and hybrid nanofluid prepared at concentrations of 0.04 and $0.10 \mathrm{vol} . \%$, flowing through the heat exchanger at three Reynolds numbers of 10,000, 15,000, and 20,000. The heat exchanger unit was modeled using ANSYS FLUENT software package in 3-D mode. The achievements of this study can lead to an efficient design of the heat exchangers.

\section{Numerical Model}

\subsection{Physical Model}

Figure 1 shows a schematic illustration of the studied shell and tube heat exchanger in the present work. The length $L_{t}$ and diameter $D_{s}$ of the heat exchanger were $450 \mathrm{~mm}$ and $70 \mathrm{~mm}$, respectively. The hybrid nanofluid flows through the tube side, and the flow direction was counter current. It meant water flowed through the shell. The geometrical configuration and detailed specifications of the heat exchanger are given in Table 2.

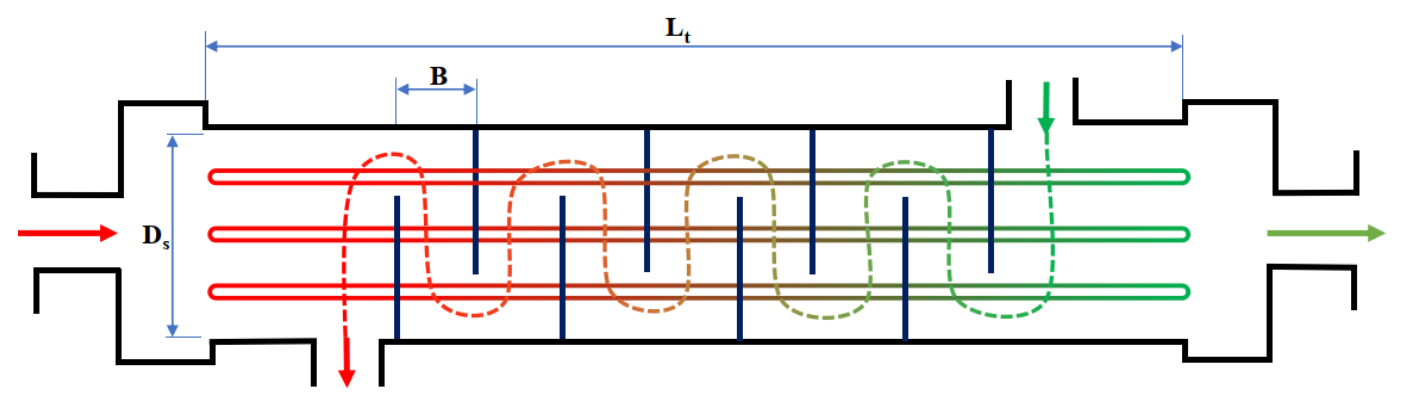

Figure 1. Schematic diagram of shell and tube heat exchanger.

Table 2. Geometrical parameters of shell and tube heat exchanger studied in this work.

\begin{tabular}{ccc}
\hline Geometry & & Dimension \\
\hline \multirow{2}{*}{ Shell side } & Inner dimeter $\left(D_{s}\right)$ & $70 \mathrm{~mm}$ \\
\cline { 2 - 3 } & Length $\left(L_{t}\right)$ & $450 \mathrm{~mm}$ \\
\hline \multirow{2}{*}{ Tube side } & Inner diameter $\left(\mathrm{d}_{\mathrm{o}}\right)$ & $10 \mathrm{~mm}$ \\
\cline { 2 - 3 } & Pitch from the center $\left(\mathrm{P}_{\mathrm{t}}\right)$ & $15 \mathrm{~mm}$ \\
\cline { 2 - 3 } & Number & $3 \times 3$ \\
\hline \multirow{2}{*}{ Baffle } & Notations degree & $55^{\circ}-90^{\circ}-135^{\circ}-180^{\circ}$ \\
& Number $(n)$ & 50 \\
\cline { 2 - 3 } & Cut $(\%)$ & $50 \mathrm{~mm}$ \\
\hline
\end{tabular}

As represented in Figure 2, baffle rotation with angles of $45^{\circ}, 90^{\circ}, 135^{\circ}$, and $180^{\circ}$ was investigated in this study. The heat exchanger contained eight baffles separated by $50 \mathrm{~mm}$ distance from each other, as shown in the computational domain illustration (see Figure 2) and including $50 \%$ cut. The tube bundle contained nine tubes with $10 \mathrm{~mm}$ outer diameter and $15 \mathrm{~mm}$ square pitch. 


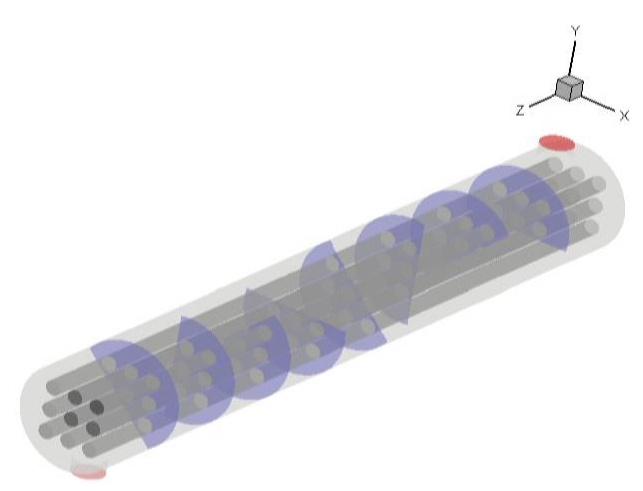

(a)

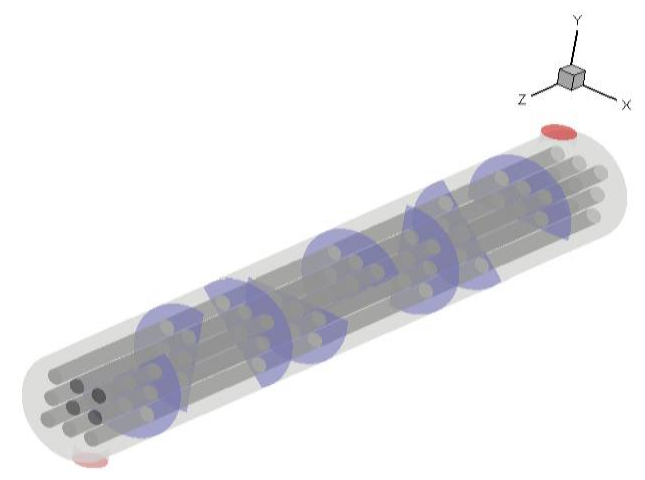

(c)

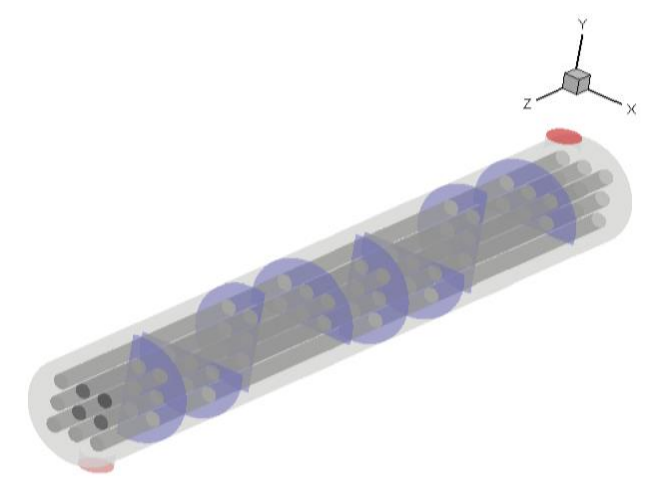

(b)

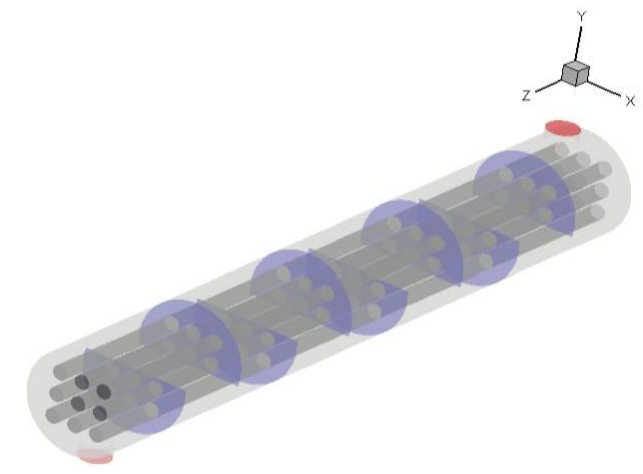

(d)

Figure 2. Schematic of the computational domain of shell and tube heat exchanger with baffle rotation angles of (a) $45^{\circ}$, (b) $90^{\circ}$, (c) $135^{\circ}$, and (d) $180^{\circ}$.

To simplify the investigation, the following boundary conditions were considered:

- The shell walls were insulated and assumed to be adiabatic.

- The gravity force was negligible.

- Nanofluid characteristics changes by temperature and the concentrations varied from 0 to $0.1 \%$.

- Nanofluids represent Newtonian behavior.

- The nanomaterials were completely dispersed in base fluid and move with the same velocity as the fluid.

- The fluid flows in shell and tube sides were incompressible and fully developed. The modelings were done in the time-dependant (unsteady) conditions, but the results were reported a long time after the initial process when the results were steady (timeindependent).

- Inlet temperature of water and Reynolds numbers were set at $\mathrm{T}_{\mathrm{w}, \text { in }}=293 \mathrm{~K}$ and $\operatorname{Re}=10,000,15,000$, and 20,000.

- A pressure outlet was chosen for the water outlet.

\subsection{Governing Equations}

The conservation equations for the 3-D homogeneous mixture model were as follows [33]:

Continuity Equation:

$$
\nabla \cdot\left(\rho_{m} V_{m}\right)=0
$$

Momentum Equation:

$$
\frac{\partial}{\partial t}\left(V_{m}\right)+\nabla \cdot\left(V_{m} V_{m}\right)=-\nabla P_{m}+\nabla \cdot\left[\mu_{m}\left(\nabla V_{m}+\nabla V_{m}^{T}\right)\right]
$$


where

$$
\mu_{m}=\sum_{Z=1}^{n} \varphi_{Z} \mu_{Z}
$$

Energy Equation:

$$
\frac{\partial}{\partial t} h_{m}+\nabla \cdot\left(h_{m} V_{m}\right)+\nabla \cdot\left(P V_{m}\right)=\nabla \cdot\left(k_{e f f} \nabla T\right)
$$

where

$$
h_{m}=\sum_{Z=1}^{n}\left(\varphi_{Z} h_{Z}\right)
$$

and

$$
k_{e f f}=\sum_{Z=1}^{n} \varphi_{Z}\left(k_{Z}+k_{t}\right)
$$

Re-Normalisation Group (RNG) $k-\varepsilon$ turbulence model:

Turbulent kinetic energy transport equation:

$$
\frac{\partial K}{\partial t}+u_{m} \frac{\partial K}{\partial x}+v_{m} \frac{\partial K}{\partial y}=\frac{\partial}{\partial x}\left(v_{m}+\frac{v_{t, m}}{\sigma_{k}}\right) \frac{\partial K}{\partial x}+\frac{\partial}{\partial y}\left(v_{m}+\frac{v_{t, m}}{\sigma_{k}}\right) \frac{\partial K}{\partial y}+P_{k, m}-\varepsilon
$$

Dissipation of turbulent kinetic energy transport equation:

$$
\frac{\partial \varepsilon}{\partial t}+u_{m} \frac{\partial \varepsilon}{\partial x}+v_{m} \frac{\partial \varepsilon}{\partial y}=\frac{\partial}{\partial x}\left(v_{m}+\frac{v_{t, m}}{\sigma_{\varepsilon}}\right) \frac{\partial \varepsilon}{\partial x}+\frac{\partial}{\partial y}\left(v_{m}+\frac{v_{t, m}}{\sigma_{\varepsilon}}\right) \frac{\partial \varepsilon}{\partial y}+C_{1} \frac{\varepsilon}{K} P_{k, m}+C_{2} \frac{\varepsilon^{2}}{K}+C_{3} \frac{\varepsilon}{K} G_{k, m}-R_{\varepsilon, m}
$$

The eddy viscosity derived from Prandtl-Kolomogorov relationship:

$$
v_{t, m}=C_{\mu} f_{\mu} \frac{K^{2}}{\varepsilon}
$$

The turbulence kinetic energy production term, $P_{k}$, can be expressed as:

$$
P_{k, m}=v_{t, m}\left[2\left(\frac{\partial u_{m}}{\partial x}\right)^{2}+2\left(\frac{\partial v_{m}}{\partial x}\right)^{2}+\left(\frac{\partial u_{m}}{\partial y}+\frac{\partial v_{m}}{\partial y}\right)^{2}\right]
$$

The $R_{\varepsilon, m}$ term in RNG $k-\varepsilon$ model is defined by:

$$
R_{\varepsilon, m}=\frac{C_{\mu, m} \eta^{3}\left(1-\frac{\eta}{\eta_{0}}\right)}{1+\beta \eta^{3}} \frac{\varepsilon^{2}}{K}
$$

where:

$$
\eta=\frac{S K}{\varepsilon}
$$

The constant $C_{3}$, is given as:

$$
C_{3}=\tanh \left|\frac{v}{u}\right|
$$

Table 3 shows the constants for the Re-Normalisation Group (RNG) $k-\varepsilon$ turbulence model [33].

Table 3. Coefficients for RNG k- $\varepsilon$ turbulent model [33].

\begin{tabular}{cccccccc}
\hline $\boldsymbol{K}$ & $\boldsymbol{\beta}$ & $\eta_{0}$ & $\boldsymbol{C}_{\mathbf{2}}$ & $\boldsymbol{C}_{\mathbf{1}}$ & $\sigma_{\varepsilon}$ & $\sigma_{\boldsymbol{k}}$ & $\boldsymbol{C}_{\boldsymbol{\mu}}$ \\
\hline 0.41 & 0.012 & 4.38 & 1.68 & 1.42 & 1.3 & 1 & 0.0845 \\
\hline
\end{tabular}




\subsection{Thermophysical Characteristics of Hybrid Nanofluid}

Hybrid nanofluids were prepared using graphene nanoplatelets and silver nanoparticles. The modeling outputs were carried out for distilled water as well as hybrid nanofluid's flow with volumetric concentrations of $0.04 \%$ and $0.1 \%$. Thermophysical properties of distilled water and hybrid nanofluids such as density, dynamic viscosity, and thermal conductivity are calculated via information given in the literature [34] and enlisted in Table 4 . The heat capacity of the fluid was considered constant and equal to $4182 \mathrm{~J} / \mathrm{kg} \mathrm{K}$.

Table 4. Thermophysical characteristics of water and hybrid nanofluid at various temperatures [34].

\begin{tabular}{|c|c|c|c|c|}
\hline Nanofluid Concer & Temperature (K) & $\rho\left(\mathrm{kg} / \mathrm{m}^{3}\right)$ & $k(\mathrm{~W} / \mathrm{m} . \mathrm{K})$ & $\mu(\mathrm{kg} / \mathrm{m} . \mathrm{s})$ \\
\hline \multirow{5}{*}{$0.1 \%$} & 293.27 & 998.942 & 0.67 & 0.00127 \\
\hline & 298.28 & 997.808 & 0.68 & 0.00113 \\
\hline & 303.24 & 996.288 & 0.7 & 0.00103 \\
\hline & 308.25 & 994.712 & 0.73 & 0.00097 \\
\hline & 313.25 & 992.923 & 0.769 & 0.00092 \\
\hline \multirow{10}{*}{$0.04 \%$} & 293.15 & 998.12 & 0.617 & 0.00118 \\
\hline & 298.15 & 996.93 & 0.623 & 0.00106 \\
\hline & 303.2 & 995.433 & 0.628 & 0.00095 \\
\hline & 308.2 & 993.974 & 0.648 & 0.00088 \\
\hline & 313.2 & 992.229 & 0.688 & 0.00083 \\
\hline & 293.19 & 997.898 & 0.591 & 0.0011 \\
\hline & 298.17 & 996.675 & 0.601 & 0.00097 \\
\hline & 303.15 & 995.299 & 0.611 & 0.00086 \\
\hline & 308.19 & 993.694 & 0.620 & 0.00079 \\
\hline & 313.17 & 991.955 & 0.631 & 0.00071 \\
\hline
\end{tabular}

\subsection{Numerical Procedure}

To develop the computational fluid dynamic models, the simulation was performed using the finite volume method (FVM) [35] via ANSYS FLUENT 2020 software. The pressure-velocity equations were coupled together by implementing the SIMPLE (Semi Implicit Method for Pressure Linked Equations) algorithm [35,36], while the discretization of equations was defined by implementing the second-order upwind $[37,38]$. The residual criteria were set equal to $10^{-7}$ for all equations to ensure the calculations' accuracy $[33,39]$. The turbulence was modeled using RNG $k-\varepsilon$. This model has a preference to similar models like Standard $k-\varepsilon$, as it produces more precise results, specifically in the flow around a curvature [40] and swirl flows [41].

To calculate the hydraulic diameter, the following equation was used:

$$
D_{e}=\frac{4\left(P_{t}^{2}-0.25 \times \pi d_{0}^{2}\right)}{\pi d_{0}}
$$

Reynolds number was also calculated based on the following equation:

$$
\operatorname{Re}=\frac{\rho \cdot V \cdot D_{e}}{\mu}
$$

Heat transfer coefficient $(h)$ was obtained employing logarithmic mean temperature difference (LMTD) method, which is described by temperature distance between outlet and inlet of water and wall as:

$$
\begin{gathered}
\Delta T_{L M T D}=\frac{\left(\Delta T_{\max }-\Delta T_{\min }\right)}{\ln \left(\frac{\Delta T_{\max }}{\Delta T_{\min }}\right)} \\
h=\frac{Q}{A_{0} \Delta T_{L M T D}} \\
Q=\dot{m} C_{P}\left(T_{w, \text { out }}-T_{w, \text { in }}\right)
\end{gathered}
$$


Moreover, two essential variables were introduced as follows:

Nusselt number:

$$
N u=\frac{h \cdot D_{e}}{k}
$$

Notably, thermal conductivity, $k$, is constant and is equal to its value for distilled water at inlet temperature.

Friction factor:

$$
f=\frac{2 \Delta P}{\rho V^{2} \frac{L}{D_{e}}}
$$

where $\Delta P$ is defined as the value of the pressure drop obtained via CFD model.

\subsection{Model Validation}

Model validation was performed by comparing some of the present study outputs with the results already reported in the literature in two prior studies. In Figure 3, the Nusselt number of the present model at different Reynolds numbers is compared with the results reported by Mellal et al. [42]. The comparison was made on water flowing through a shell and tube heat exchanger with shell diameter, tube diameter, length, and the number of baffles of $135 \mathrm{~mm}, 20 \mathrm{~mm}, 640 \mathrm{~mm}$, and 6, respectively. As shown in the comparing plot, the modeling outputs were in the best agreement with Mellal et al. [42] data.

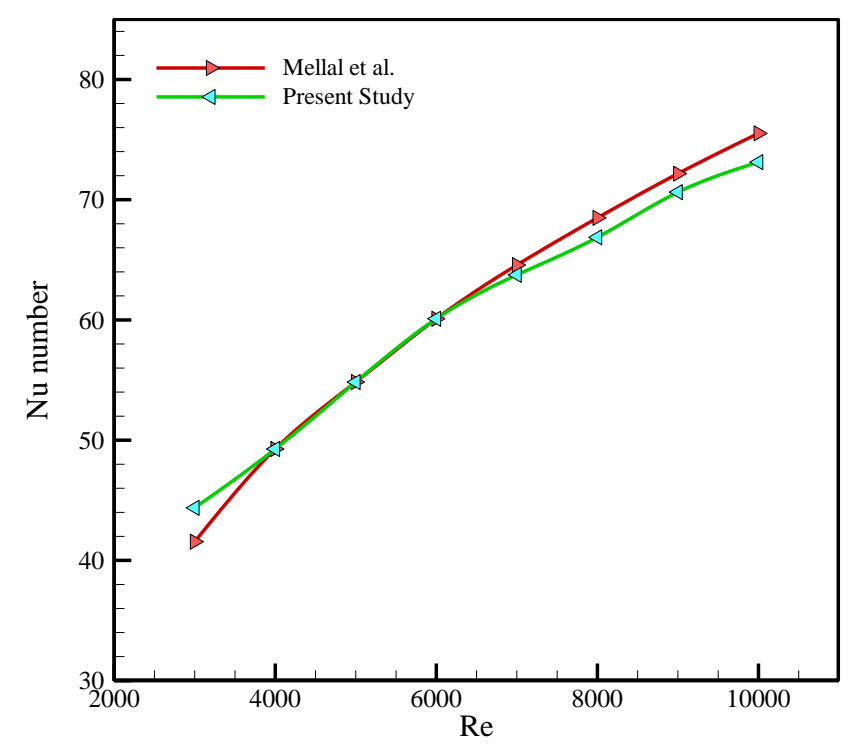

Figure 3. Comparison of Nusselt number of the present study and Mellal et al. [42].

Further model validation was carried out on the study of Sundar et al. [43], in which the Nusselt numbers were obtained for hybrid nanofluid-based water containing MWCNT$\mathrm{Fe}_{3} \mathrm{O}_{4}$ nanoparticles. Sundar et al. [43] studied a horizontal copper tube with a length of $1.75 \mathrm{~m}$ and an outer diameter of $0.016 \mathrm{~m}$, where constant heat flux was applied on the outer side of the tube. The data used for the comparison are 0.1 vol.\% nanofluids at various Re. As shown in Figure 4, a reasonable accommodation of Nusselt numbers between current calculated data and Sundar et al. [43] was apparent. 


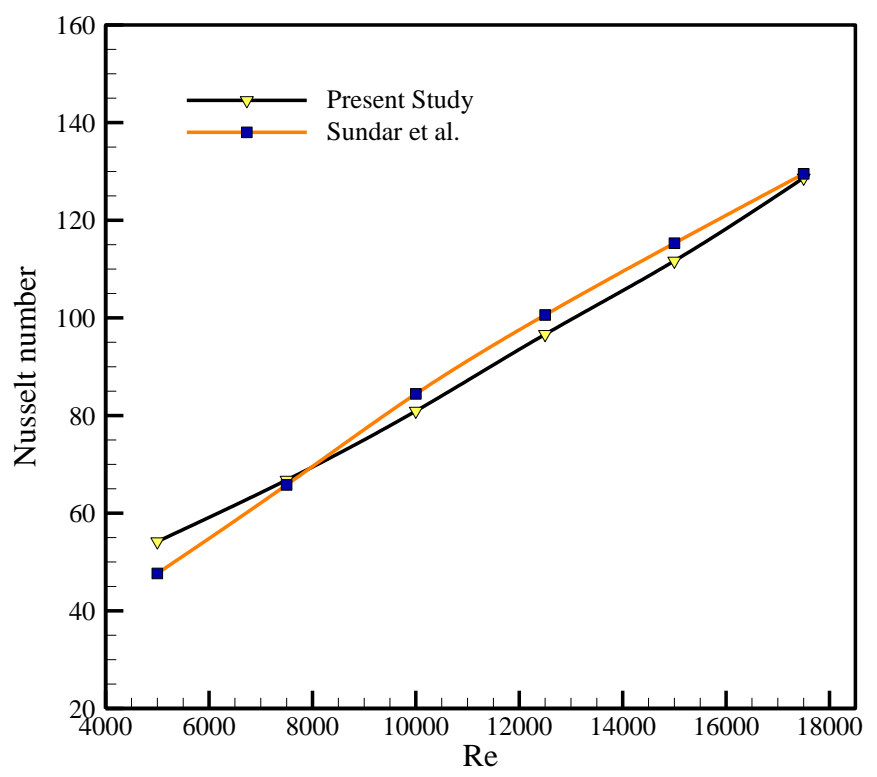

Figure 4. Comparison of calculated Nusselt numbers and those of Sundar et al. [43] study.

To validate the hybrid nanofluid modeling through the heat exchanger, the friction factor data from the experimental work of Yarmand et al. [34] were used, and the rough comparison was made between the results of our study and those reported by Yarmand et al. [34] as plotted in Figure 5 at heat flux equal to $600 \mathrm{~W} / \mathrm{m}^{2}, \mathrm{~L}=1.4 \mathrm{~m}, \mathrm{D}=0.01 \mathrm{~m}$ and $0.1 \%$ solid volume fraction. The present study modeling has shown good agreement against the experimental data. The difference between the results could be due to the possible uncertainties of Yarmand et al. [34] study, which did not report on that paper.

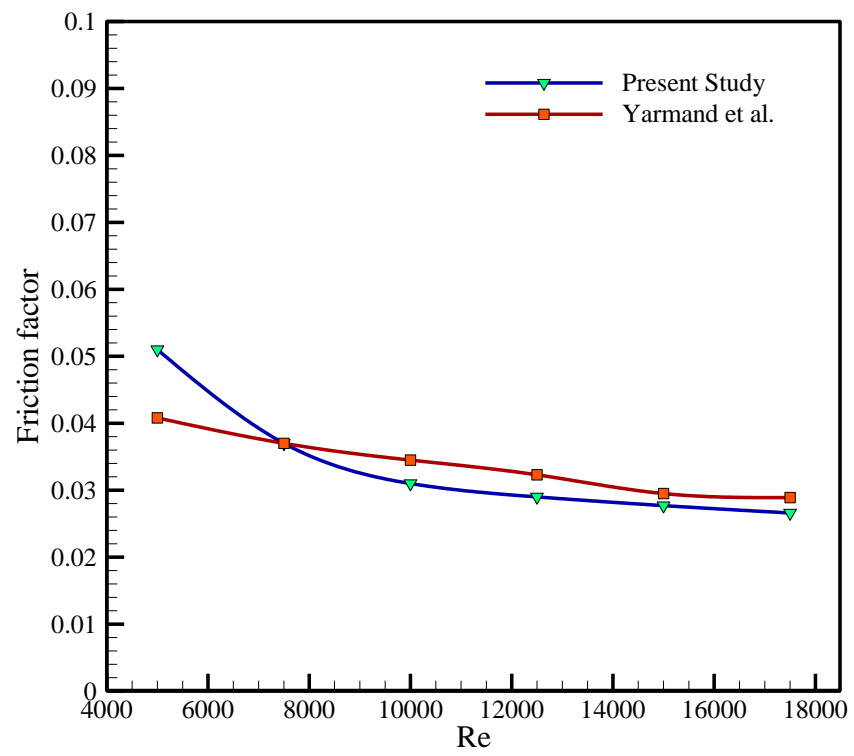

Figure 5. Comparison of friction factor of the current study and Yarmand et al. [34] investigation.

The above comparisons indicated that the present modeling had enough reliability, and data were reliable for further analysis.

\subsection{Grid Independence Study}

The grid independence test was utilized to ensure the model's outcome is independent of the number of the mesh, mesh structure and size. As shown in Figure 6, the computational domain was meshed by taking accounting unstructured tetrahedral elements. Table 5 
shows the grid independence study for $\operatorname{Re}=10,000$ and no baffle case. It was identified that the optimum number of cells was 1,442,955 to achieve the best results and sufficient accuracy and optimum use of computational resources.

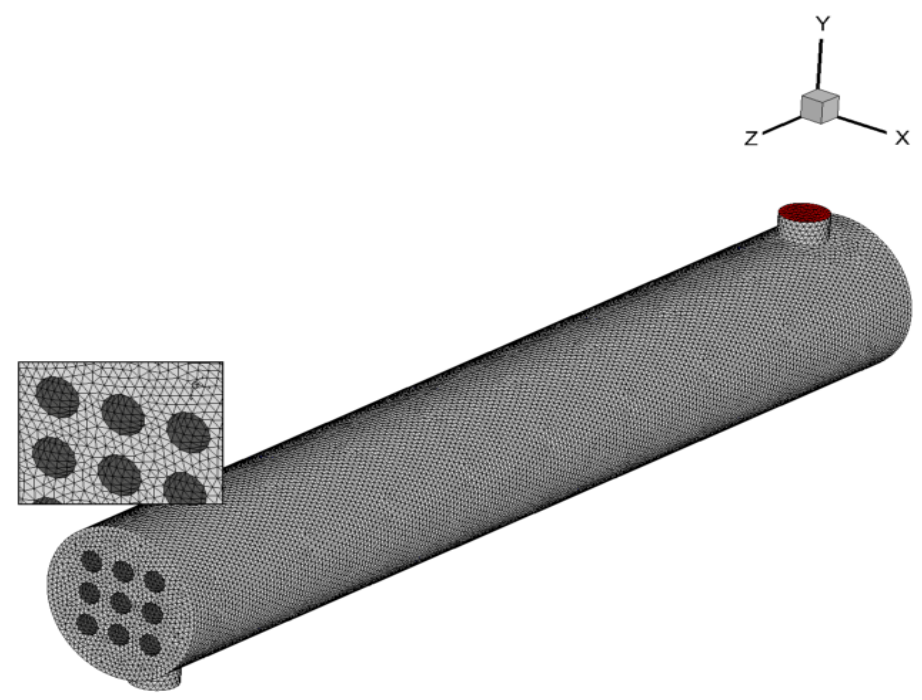

Figure 6. Created meshes for the computational domain of shell and tube heat exchanger.

Table 5. Mesh independence study.

\begin{tabular}{ccccccccc}
\hline Number of Grids & $\mathbf{5 3 6 , 7 1 3}$ & $\mathbf{9 6 1 , 1 9 2}$ & $\mathbf{1 , 0 8 6 , 0 5 7}$ & $\mathbf{1 , 1 5 1 , 1 1 5}$ & $\mathbf{1 , 3 7 5 , 6 0 8}$ & $\mathbf{1 , 4 4 2 , 9 5 5}$ & $\mathbf{1 , 8 3 0 , 8 5 5}$ & $\mathbf{2 , 2 1 8 , 7 5 5}$ \\
\hline $\mathrm{Nu}$ & 24.947 & 25.902 & 25.937 & 26.078 & 26.115 & 26.699 & 26.836 & 26.974 \\
\hline
\end{tabular}

\section{Result and Discussion}

In this section, the results of Nusselt number, friction factor, and pressure drop through shell and tube heat exchanger are presented at hybrid nanofluid concentrations of $0 \%$ to $0.1 \%$, Reynolds numbers of 10,000 to 20,000 , and baffle angles of $45^{\circ}$ to $180^{\circ}$.

\subsection{Heat Transfer Performance}

The heat transfer coefficients of nanofluids and water are displayed in Figure 7 as a function of Re for all baffle arrangements. As was expected, increasing Re or nanoparticle volume fraction augmented the heat transfer coefficient. Additionally, rising the baffle angles from $45^{\circ}$ to $180^{\circ}$ caused an enhancement in the heat transfer coefficient. Nevertheless, for baffle angles of $45^{\circ}, 90^{\circ}, 135^{\circ}$, and $180^{\circ}$ heat transfer enhancements $99.05 \%$, $109.75 \%, 111.03 \%$, and $107.16 \%$ were obtained when Re increased from 10,000 to 20,000 and at the same time nanofluid concentration boosted from 0 to $0.1 \mathrm{vol} . \%$. It is clear that more rotation in baffle angles led to a heat transfer enhancement which could have a maximum at $135^{\circ}$. At a specific Re, heat transfer coefficient enhancement had an ever-increasing trend by increasing nanofluid concentration for baffle angles of $45^{\circ}$ to $180^{\circ}$; however, the heat transfer enhancements for baffle arrangement with $135^{\circ}$ and $180^{\circ}$ were very close to each other. 


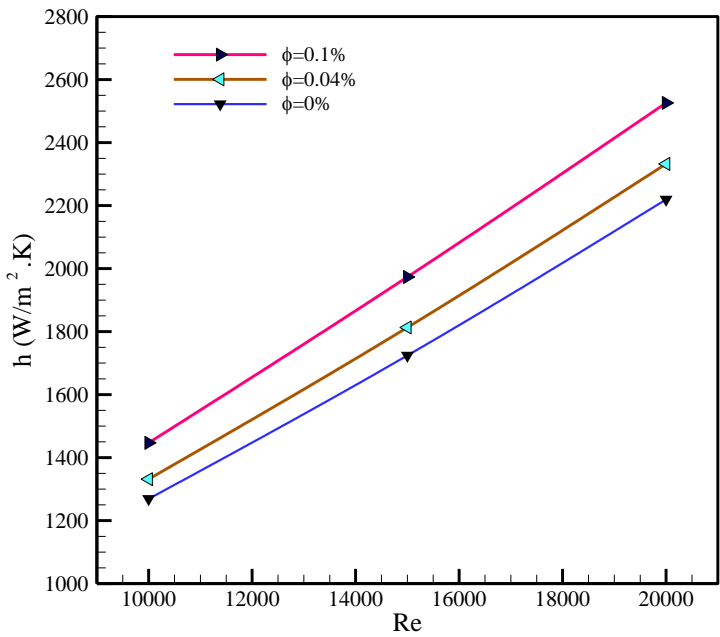

(a)

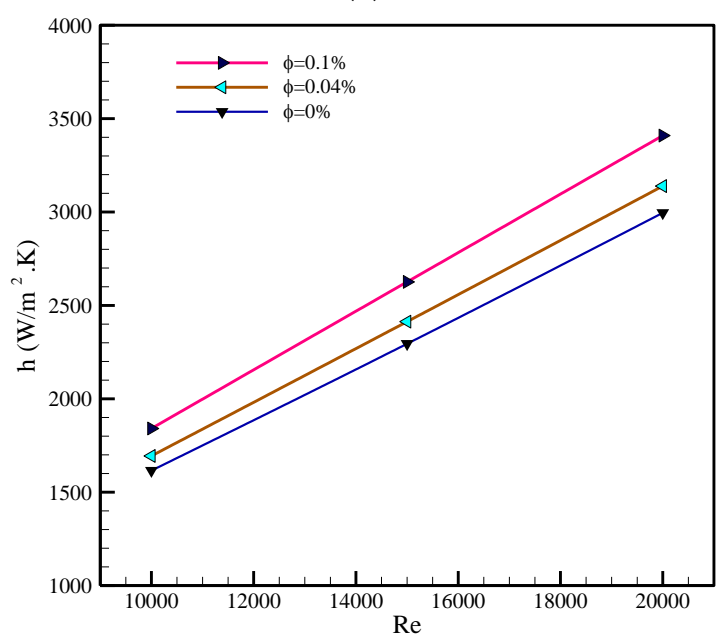

(c)

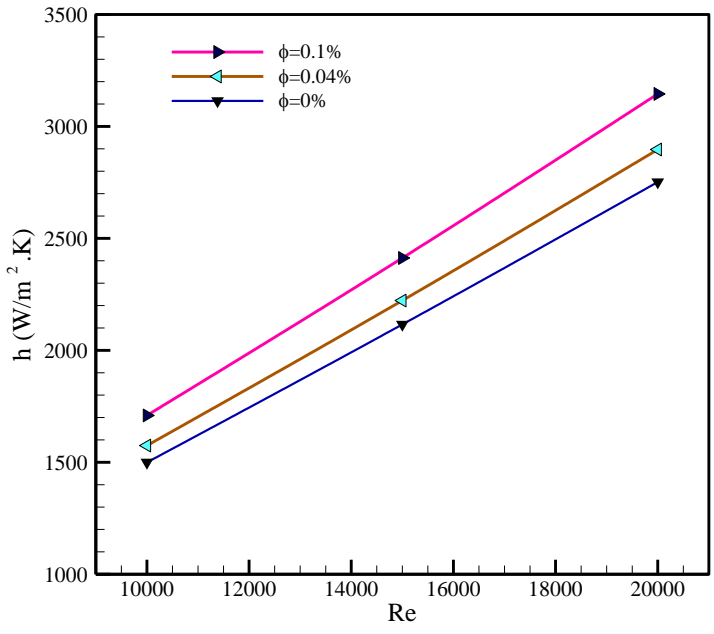

(b)

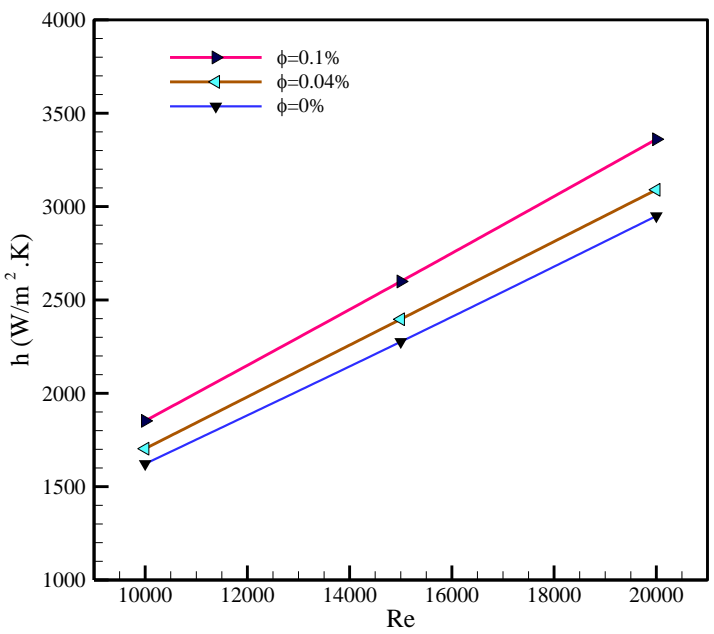

(d)

Figure 7. Heat transfer coefficient against Reynolds number at various solid volume fractions with baffle angles of (a) $45^{\circ}$, (b) $90^{\circ}$, (c) $135^{\circ}$, and (d) $180^{\circ}$.

In Figure 8, the heat transfer coefficients of both nanofluids and distilled water are compared at different Reynold numbers and baffle angles. The increasing trend of heat transfer is obvious from the figures, which augments with Re and baffle angle increment at each nanoparticle volume fraction. The enhancing trend was repeated for all concentrations. However, the values of heat transfer coefficients of two prior baffle angles were obtained with a big difference; they were similar for the two last angles. Regarding the performance of transferring heat through the heat exchanger, the baffle arrangement with $135^{\circ}$ acted like the $180^{\circ}$ arrangement. Nonetheless, the difference between the heat transfer coefficients corresponding to baffle angles $135^{\circ}$ and $180^{\circ}$ became more, by increasing Re. Of course, this observation was expected because, at high Re, the role of baffle angles in fluctuating the fluid flow became more significant. Thus, the higher the flow rate, the higher the fluid flow mixing, and subsequently, the higher the heat transfer coefficient. 


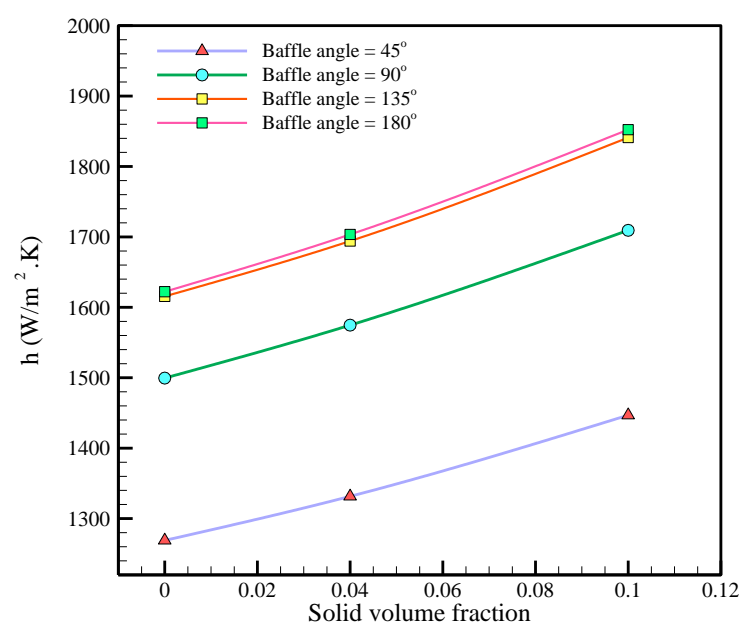

(a)

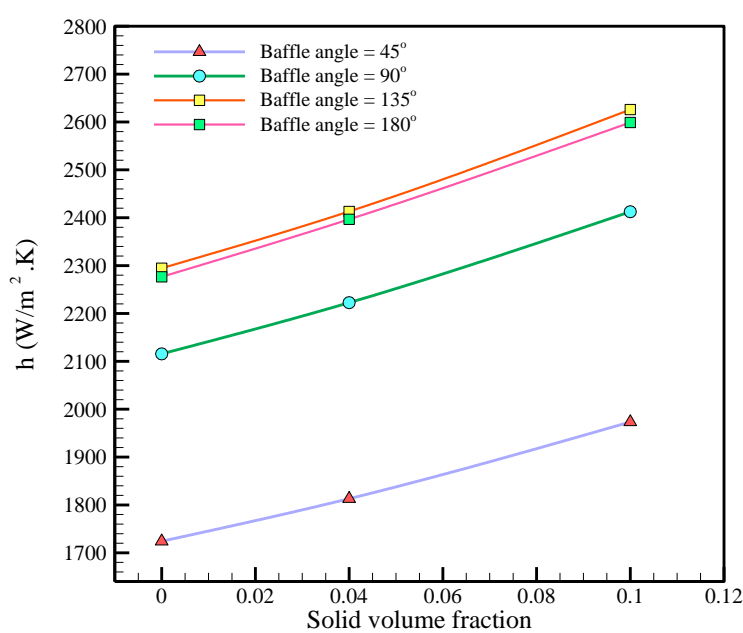

(b)

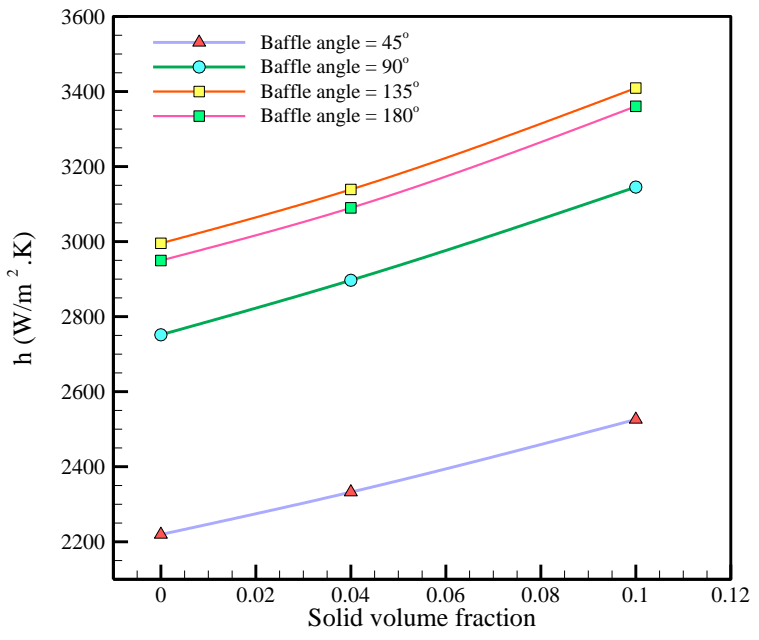

(c)

Figure 8. Heat transfer coefficient against solid volume fraction at various baffle angles with Reynolds numbers of (a) 10,000, (b) 15,000 , and (c) 20,000 .

As depicted in Figure 9, the influence of the concentration of hybrid nanofluid on $\mathrm{Nu}$ was demonstrated at various Reynolds numbers for each baffle angle. As seen, increasing Re and nanofluid concentration for all baffle angles resulted in enhancing the Nusselt number. This is because nanofluid's thermal conductivity was enhanced due to nanoparticles' presence compared to the water. This is primarily due to the presence of micro-scale phenomena such as Brownian motion, which resulted in enhancement of thermal conductivity such as $13.81 \%, 14.31 \%, 13.81 \%$, and $13.93 \%$ enhancement in Nusselt number for baffle angles of $45^{\circ}, 90^{\circ}, 135^{\circ}$, and $180^{\circ}$ by adding only $0.1 \%$ solid volume fraction in $\operatorname{Re}=20,000$. 


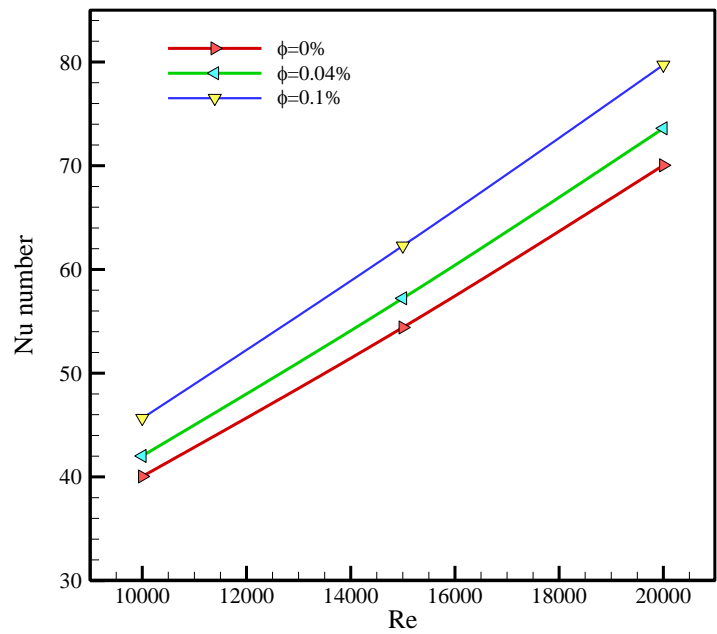

(a)

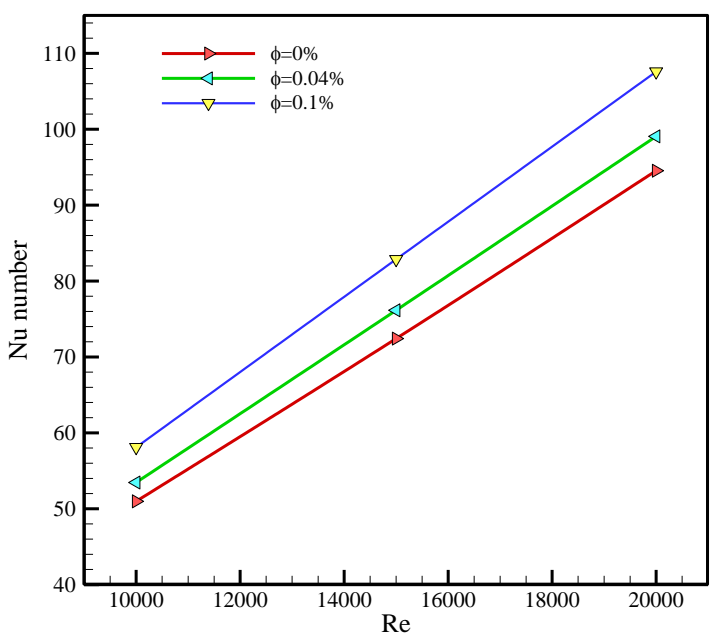

(c)

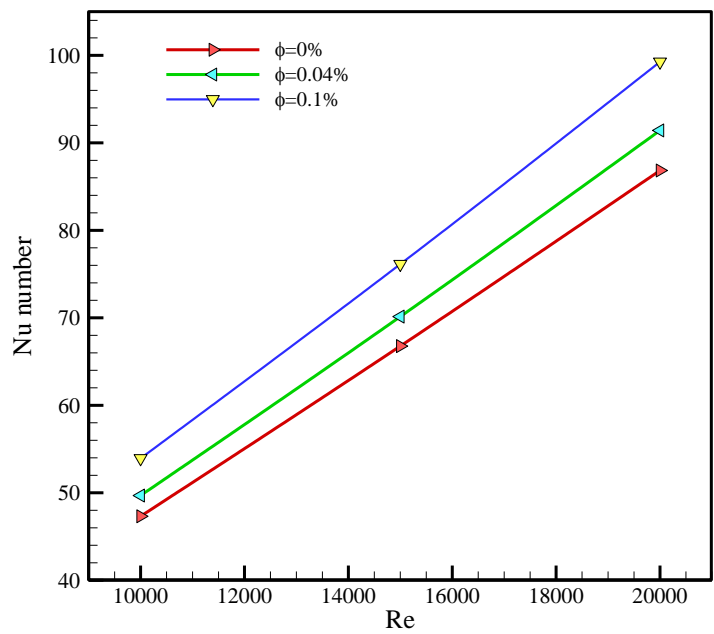

(b)

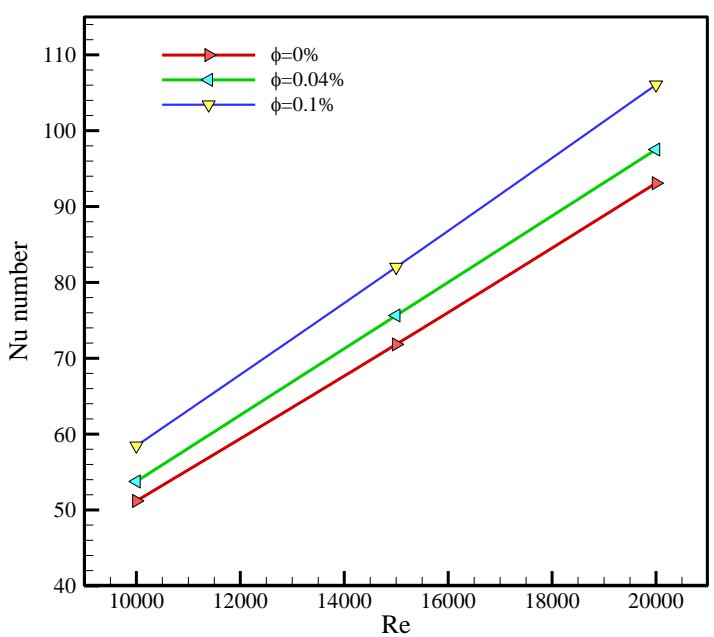

(d)

Figure 9. Nusselt number against Reynolds number at various solid volume fractions with baffle angles of (a) $45^{\circ}$, (b) $90^{\circ}$, (c) $135^{\circ}$, and (d) $180^{\circ}$.

Utilizing baffle in the shell side of heat exchangers had some advantages, such as tube bending, preventing the tubes from moving by applying for a supporting role through the shell side. However, the key feature of using baffles was to guide the fluid flow within the tube bundle, which augmented the thermal efficiency and heat transfer coefficient. Baffles led to more local agitation and turbulence and reaching fresh fluid to any hot surfaces of the tube bundle. Meanwhile, adding nanoparticles to the fluid flow caused a further increase in the Nusselt number than distilled water. This can be seen in the results represented in Figure 10. The Nusselt number's variation with Reynolds number at various baffle angles is shown in this figure. The effect of baffle angle on the water flow characteristics that of observed for hybrid nanofluid. It meant that the $\mathrm{Nu}$ was increased by increasing the angle from $45^{\circ}$ to $180^{\circ}$, and for water, the increment of the Nusselt number almost equaled the one calculated for hybrid nanofluid.

Notably, arranging baffles with $45^{\circ}$ did not have adequate performance compared to other angles. Additionally, Nu numbers for heat exchanger with baffle angles of $135^{\circ}$ and $180^{\circ}$ had no significant difference. While, by increasing Re, the small gap between $\mathrm{Nu}$ of the heat exchanger with those angles smoothly increases. Generally, changing angles by $135^{\circ}$ and $180^{\circ}$ indicated better thermal performance through the heat exchanger; baffles rotating with $135^{\circ}$ has $27.24 \%$ and $34.96 \%$ higher Nu compared to rotating with $45^{\circ}$ at $\operatorname{Re}=10,000$ and 20,000, respectively. The interesting point was the Nu increment for baffle angles of 
$135^{\circ}$ was higher than that of $180^{\circ}$; using baffle arrangement with $180^{\circ}$ at $\operatorname{Re}=20,000$ made $\mathrm{Nu} 32.9 \%$ more than using $45^{\circ}$. This referred to the better velocity distribution, which we will discuss later.

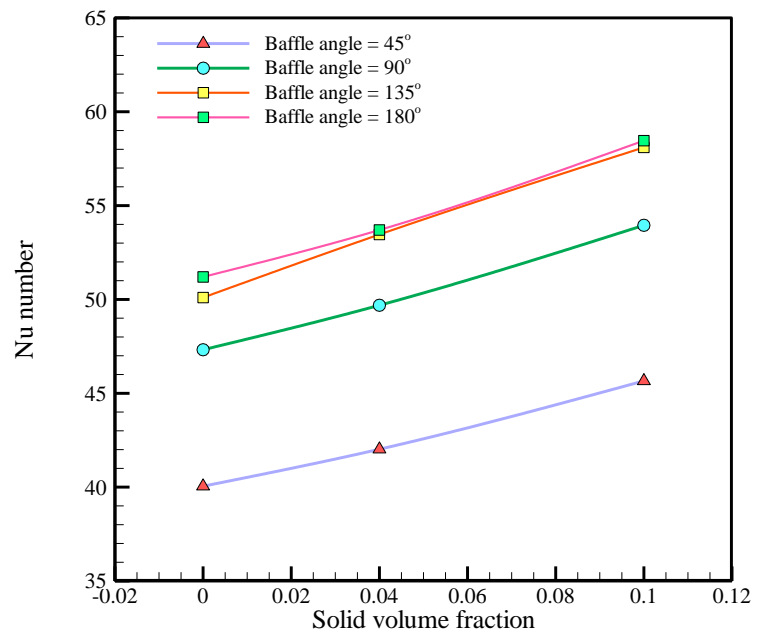

(a)

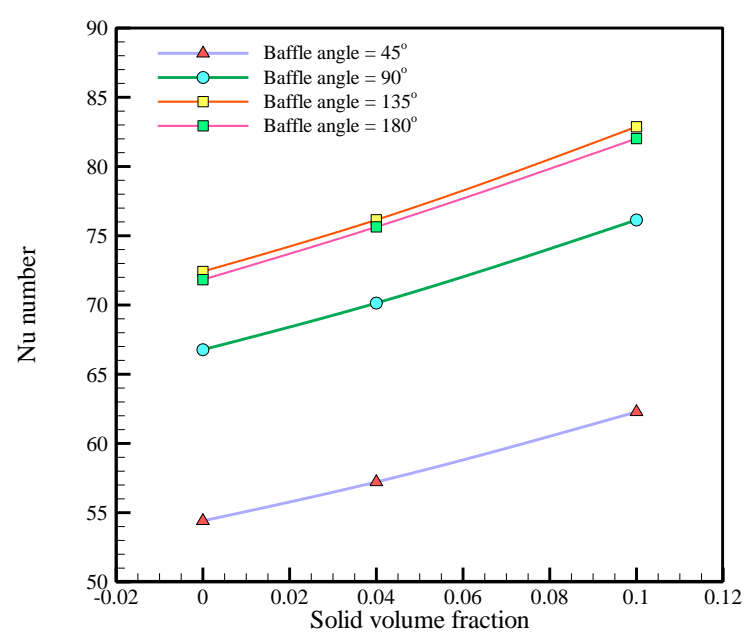

(b)

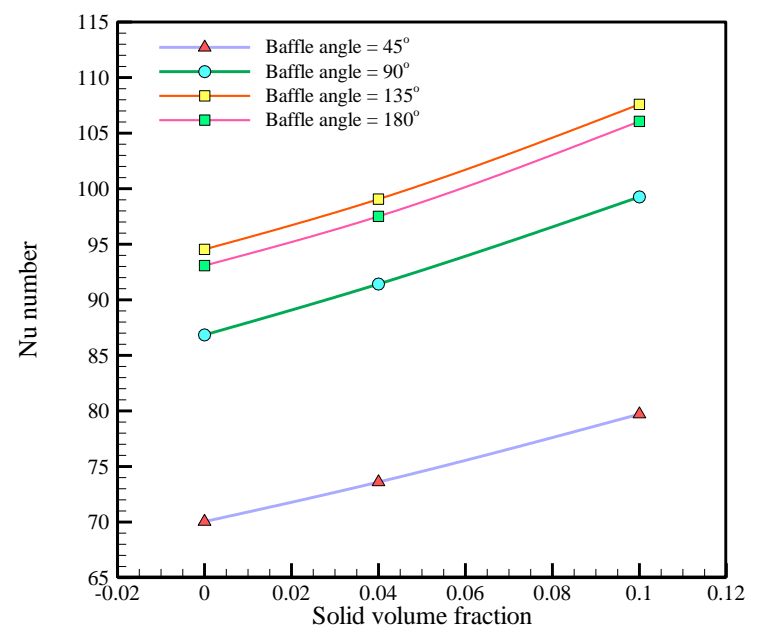

(c)

Figure 10. Nusselt number against solid volume fraction at various baffle angles with Reynolds numbers of (a) 10,000, (b) 15,000 , and (c) 20,000.

\subsection{Friction Factor}

Figure 11 shows the calculated friction factor of hybrid nanofluid through the heat exchanger for different solid volume fractions for each baffle angle. As shown, each baffle angle applied a unique trend to the friction factor. In general, the friction factor trends of all baffle angles were the same, and with increasing the Reynolds number, a higher friction factor was registered. However, the friction factor of hybrid nanofluid was more significant than distilled water. This is because of the nanoparticles' presence, which created larger friction forces due to the interaction between nanoparticles and water layers around the nanoparticles. In heat exchangers with $45^{\circ}$ and $135^{\circ}$ baffle angles, increasing Re from 15,000 to 20,000, the friction factor's value was reduced. As perceived from Equation (20), the friction factor was affected by length, hydraulic diameter, pressure drop, and velocity. In the present work, the first two parameters were constant. According to Figure 13, the value of the pressure drop was relatively constant for all cases. Therefore, velocity was the critical parameter affecting the friction factor. At high Re, baffle rotation with the angle of $45^{\circ}$ and $135^{\circ}$ led the fluid flow to a spiral trajectory line (i.e., meat grinder), which lowered the flow 
blocking. As a result, it helped to increase the velocity. Consequently, the friction factor reduced. This argument was not valid for two other angles because the spiral route did not form during the shell side path. However, the friction factor changed in baffle angles of $90^{\circ}$ and $180^{\circ}$ were not considerable, while friction factor values were almost identical.

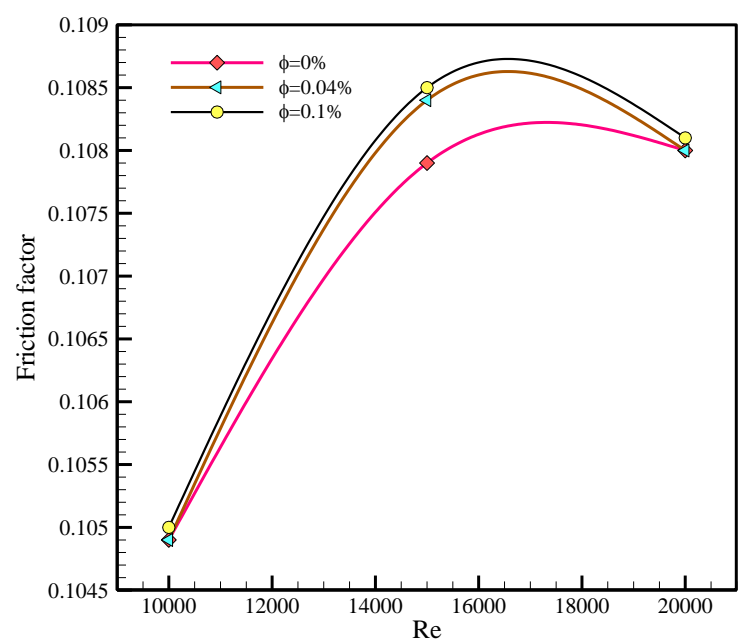

(a)

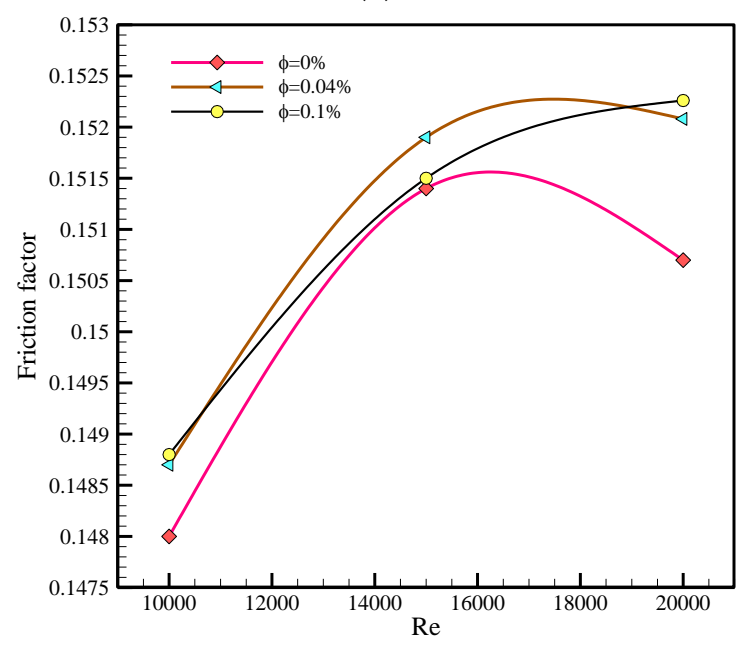

(c)

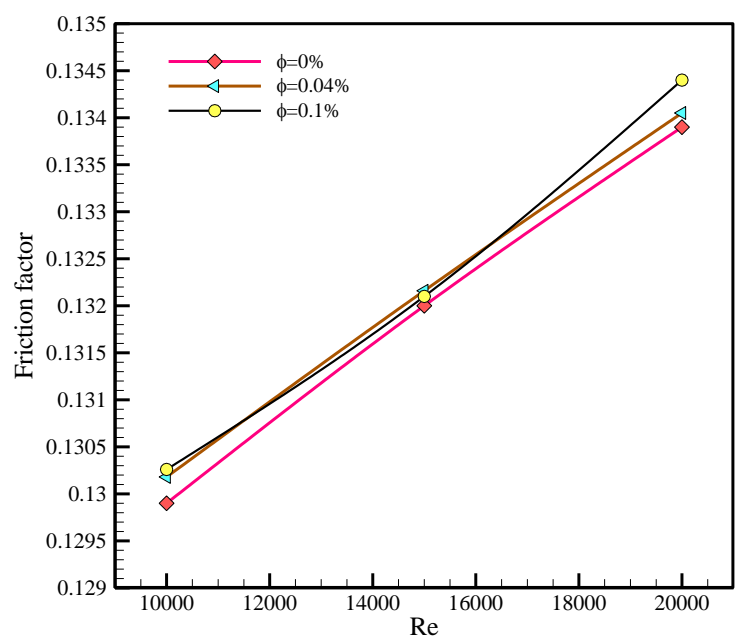

(b)

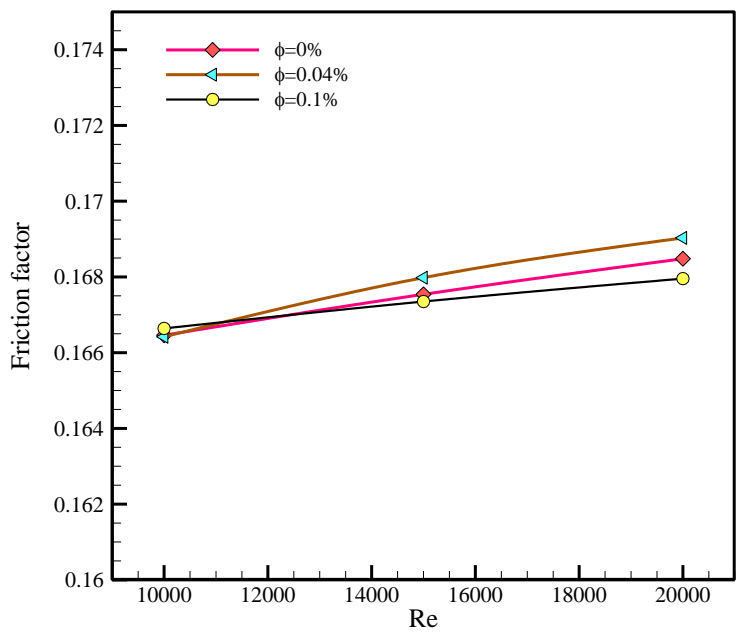

(d)

Figure 11. Friction factor against Reynolds number at various solid volume fractions through shell and tube heat exchanger with baffle angle of (a) $45^{\circ}$, (b) $90^{\circ}$, (c) $135^{\circ}$, and (d) $180^{\circ}$.

The variation of friction factor with baffle angle is plotted in Figure 12 at various Reynolds numbers for $0.1 \%$ solid volume fraction. As can be seen, increasing Re had no significant effect on friction factor, especially at higher Re. However, increasing the baffle angles from $45^{\circ}$ to $180^{\circ}$ incorporated remarkable augmentation in friction factor that causes $55.27 \%$ higher friction factor. However, each $45^{\circ}$ increase in baffle angle enhanced $24.1 \%$, $14.19 \%$, and $11.96 \%$ for $\operatorname{Re}=10,000$. The same percentages were obtained at other Reynolds numbers as well. Baffles with $180^{\circ}$ rotation have the highest flow blocking due to zigzag flow direction, which increased the friction factor. Arranging baffles with an angle of $45^{\circ}$ created more space inside the shell side and had lower flow blocking than other angles. 


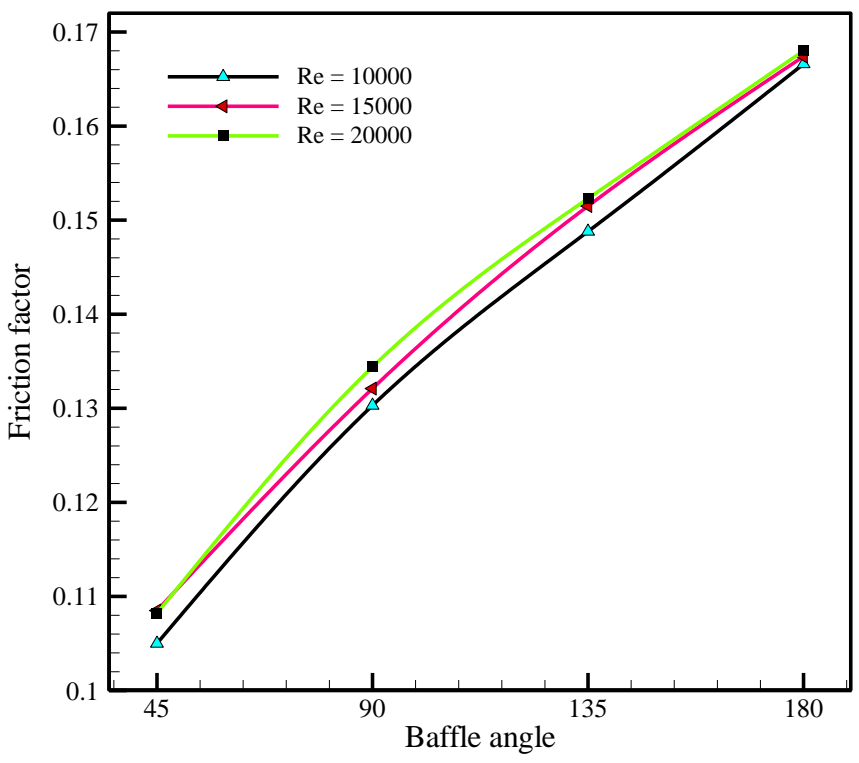

Figure 12. Variation of friction factor against baffle angle for $0.1 \%$ solid volume fraction at different Reynolds numbers.

On the other hand, the role of vortex formation was more pronounced. The friction factor increased due to the increase in vortex formation probability by increasing the baffles' angle. This could change the fluid flow path, and then, by increasing the friction factor, the pressure drop was augmented.

\subsection{Pressure Drop}

The pressure drop value was a key parameter affecting the pumping cost that one had to "pay" for the higher heat transfer. The baffles arrangements considerably affected the induced pressure drop into the shell side. As represented in Figure 13, the pressure drop variation with $R e$ is depicted for all ranges of baffle angle and solid volume fraction. The increasing trends of pressure drop value with Re are seen from the figures. For example, in Figure $13 a-d$, the most significant pressure drop was achieved for hybrid nanofluid. The higher nanofluid concentration caused a more considerable pressure drop. Notably, by adding nanoparticles to the distilled water, more shear stress was applied to the base fluid, which augmented the dynamic viscosity and consequently, the pressure drop increased. Therefore, it can be stated that the highest pressure drop was obtained for a heat exchanger with baffle angles of $180^{\circ}$ at $\operatorname{Re}=20,000$ for nanofluid with $0.1 \%$ solid volume fraction. Such pressure drop was almost $107.5 \%$ higher than heat exchanger with baffle angle of $45^{\circ}$ at $\operatorname{Re}=10,000$ when distilled water was the working fluid. Additionally, increasing the angle of baffles led to pressure drop augmentation. For example, at $\operatorname{Re}=20,000$, the flowing of hybrid nanofluid with $0.1 \mathrm{vol} . \%$ through the heat exchanger with baffle angle of $180^{\circ}$ led to the more considerable pressure drop, 55.3\% larger in comparison with that of calculated for baffle angle of $45^{\circ}$. This was associated with the flow path through the shell side. For baffles with $45^{\circ}$, the fluid could flow more uniformly with lower blocking. However, by increasing the baffle angle, the fluid flow path became similar to a zigzag path, making more obstacles on the fluid flow, thereby increasing the pressure drop. Overall, utilizing baffles with higher angles augmented the pressure drop. However, it provided better fluid recirculation and better heat transfer within the heat exchanger unit. 


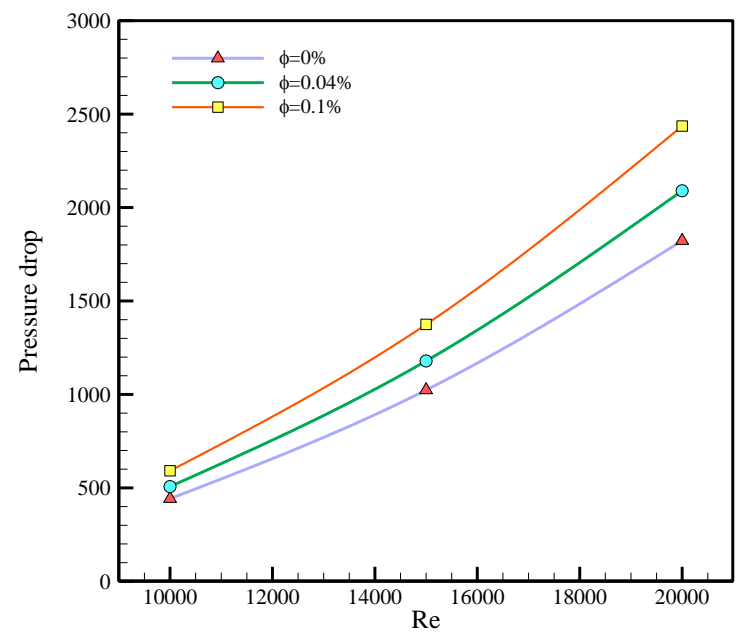

(a)

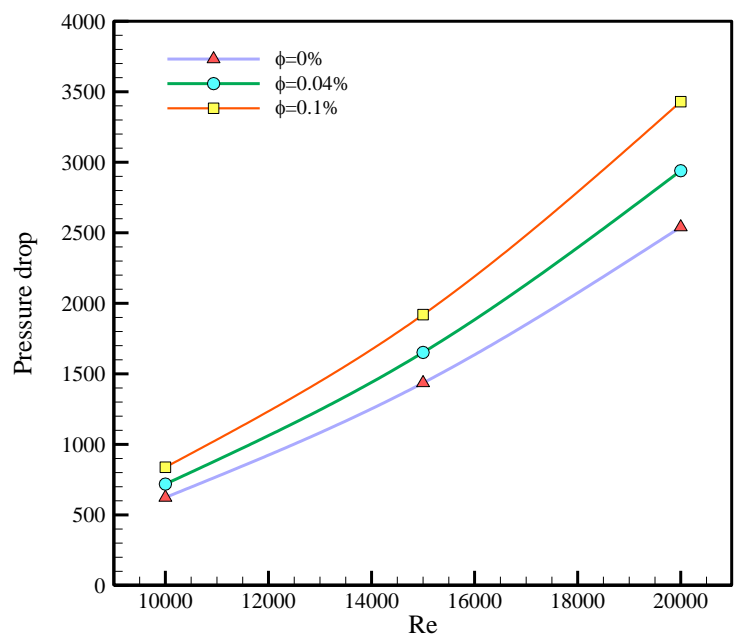

(c)

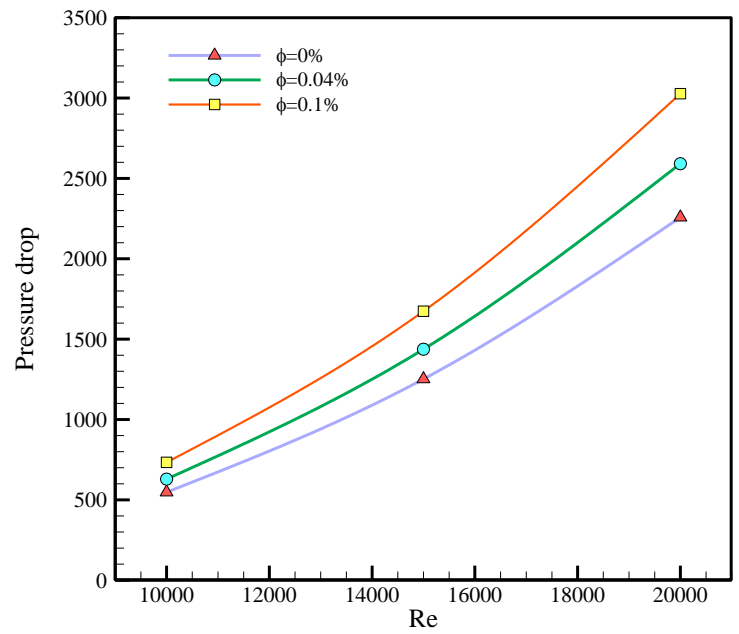

(b)

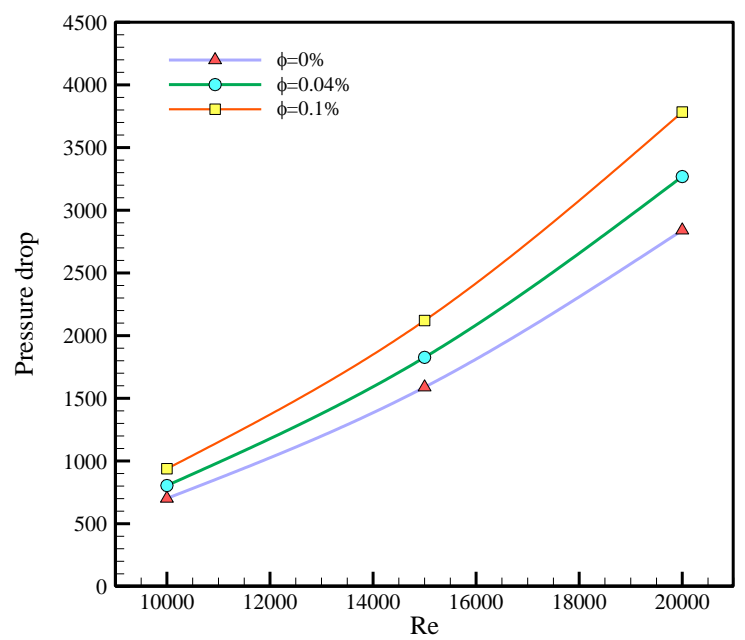

(d)

Figure 13. Pressure drop against Reynolds number at various solid volume fractions through the shell and tube heat exchanger with baffle angle of (a) $45^{\circ}$, (b) $90^{\circ}$, (c) $135^{\circ}$, and (d) $180^{\circ}$.

\subsection{Temperature Streamline Contours}

The streamline contour of the fluid inside the heat exchanger is depicted in Figure 14 for various baffle angles to investigate further the spatial temperature profile and temperature gradient across the heat exchanger. As shown, near of shell walls of the heat exchangers with baffle angles of $45^{\circ}, 90^{\circ}, 135^{\circ}$, and $180^{\circ}$, fresh working fluid (blue lines) were respectively distributed up to sixth, fourth and third baffles. However, at the middle of heat exchangers with baffle angles of $45^{\circ}$ and $90^{\circ}$, penetration of hot fluid towards the center of the heat exchanger was observed. These interpretations show that fluid flow through the shell side of heat exchangers with baffle angles of $45^{\circ}$ and $90^{\circ}$ were not appropriately distributed. Using such a baffle arrangement, the fluid could potentially leave the heat exchanger with a temperature below the target temperature. Therefore, as previously reported in Section 3.1, the $\mathrm{Nu}$ for baffle angle of $45^{\circ}$ was the lowest, meaning that baffle arrangement did not guide the flow plausibly. The relatively prominent space with a baffles angle of $45^{\circ}$ allowed the fluid to leave the heat exchanger without any local agitation or turbulence. 


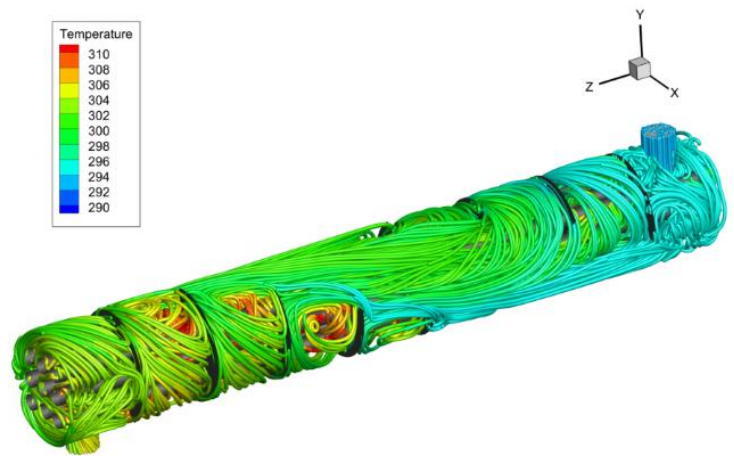

(a)

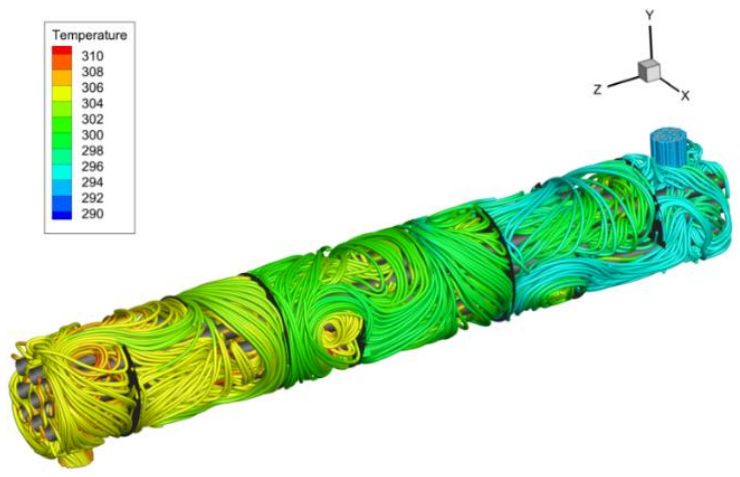

(c)

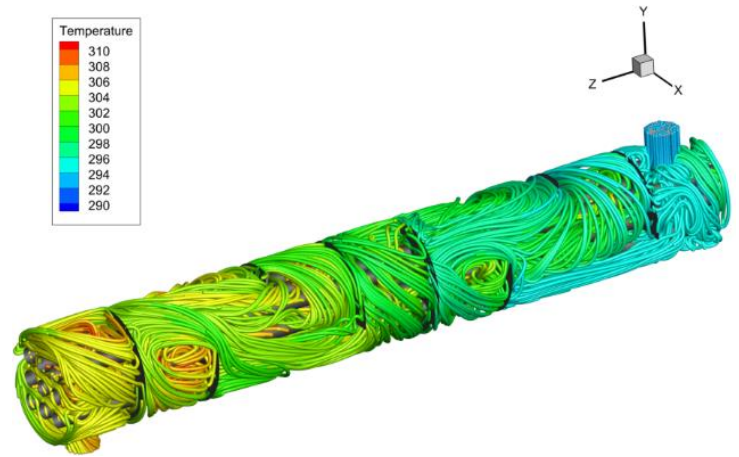

(b)

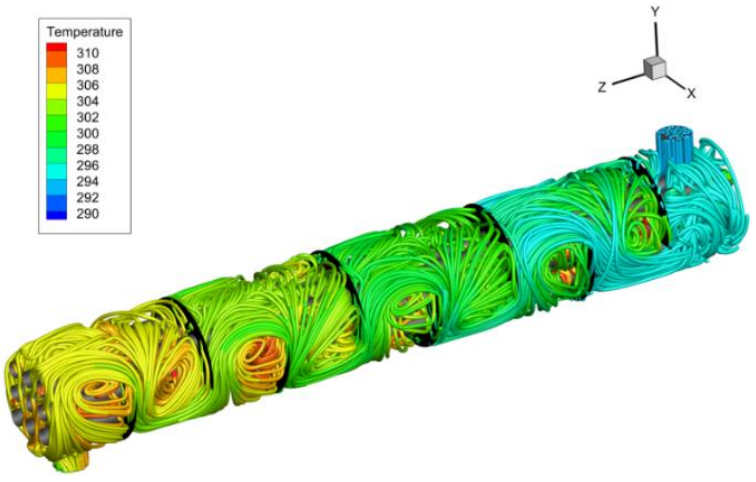

(d)

Figure 14. The streamline contour within the heat exchanger with baffle angles of (a) $45^{\circ}$, (b) $90^{\circ}$, (c) $135^{\circ}$, and (d) $180^{\circ}$.

On the other hand, in the region close to the shell side's centerline, for baffle arrangement at $135^{\circ}$ and $180^{\circ}$, no hot fluid (red lines) was seen. However, the warm (not hot) fluid (orange lines) was dominant. Especially for the baffle angle of $135^{\circ}$, the best temperature distribution was recorded visually. The four baffle angles shown in Figure 14 showed the lowest fresh fluid at the shell sidewall and hot fluid at the center region of the shell corresponding to the baffle arrangements with an angle of $135^{\circ}$. Moreover, baffle arrangement with $135^{\circ}$ was the best configuration for extracting the highest enthalpy and producing the highest outlet temperature. It was witnessed from the contours that there was no trace of fresh fluid, and the outlet included streamlines of the warm and hot fluids.

\section{Conclusions}

Hydraulic and thermal properties of a three-dimensional shell and tube heat exchanger were numerically modeled using ANSYS FLUENT software. The effect of baffle arrangement was investigated by changing the baffle angles from $45^{\circ}$ to $180^{\circ}$. Distilled water and hybrid nanofluid with concentrations of $0.04 \%$ and $0.1 \%$ were considered the working fluids. Following conclusions were also drawn:

(1) Having a higher viscosity than the base fluid, nanofluid could enhance the Nusselt number of the heat exchanger. Additionally, by increasing the baffle angle from $45^{\circ}$ to $180^{\circ}$, the Nusselt number was enhanced. However, the Nu values of $135^{\circ}$ and $180^{\circ}$ were relatively the same at low Re numbers. At high Re numbers, the calculated $\mathrm{Nu}$ corresponding to baffles angle of $135^{\circ}$ were higher.

(2) At $\operatorname{Re}=20,000$, it was identified that heat exchangers with larger baffle angles could have higher resistance against fluid flow. Thus, the friction factor and, as a result, the value of the pressure drop was augmented.

(3) It was identified that using nanofluid could create more pressure drop in comparison with the distilled water. However, this augmentation was compensated by improving the Nusselt number and the system's heat transfer coefficient. However, a techno- 
economic analysis will identify the economic viability of using nanofluids in the heat exchanger.

(4) By investigating the spatial temperature distribution along the shell side, it was identified that the optimum baffle angle of $135^{\circ}$ could provide the highest thermal performance, uniform temperature outlet and the highest Nusselt number.

Overall, hybrid nanofluid showed a potential to be utilized in a shell and tube heat exchanger. However, pumping power was augmented, which can be optimized by rearranging the configuration of the heat exchanger, size of the nanoparticles and type of the base fluid, which are recommended to be studied in the future.

Author Contributions: Conceptualization, M.A.A. and M.R.S.; methodology, M.R.S.; software, M.R.S.; validation, M.A.A. and M.R.S.; formal analysis, M.R.S.; investigation, M.A.A.; resources, M.A.A.; visualization, M.A.A. and M.R.S.; data curation, M.A.A.; writing—original draft preparation, M.A.A. and M.R.S.; writing—review and editing, M.A.A. and M.R.S.; supervision, M.A.A.; project administration, M.R.S.; funding acquisition, M.A.A. All authors have read and agreed to the published version of the manuscript.

Funding: This project was funded by the Deanship of Scientific Research (DSR), King Abdulaziz University, Jeddah, under grant No. (DF-393-135-1441). The authors, therefore, gratefully acknowledge DSR technical and financial support.

Institutional Review Board Statement: Not applicable.

Informed Consent Statement: Not applicable.

Data Availability Statement: Not applicable.

Conflicts of Interest: The authors declare no conflict of interest.

\section{Nomenclature}

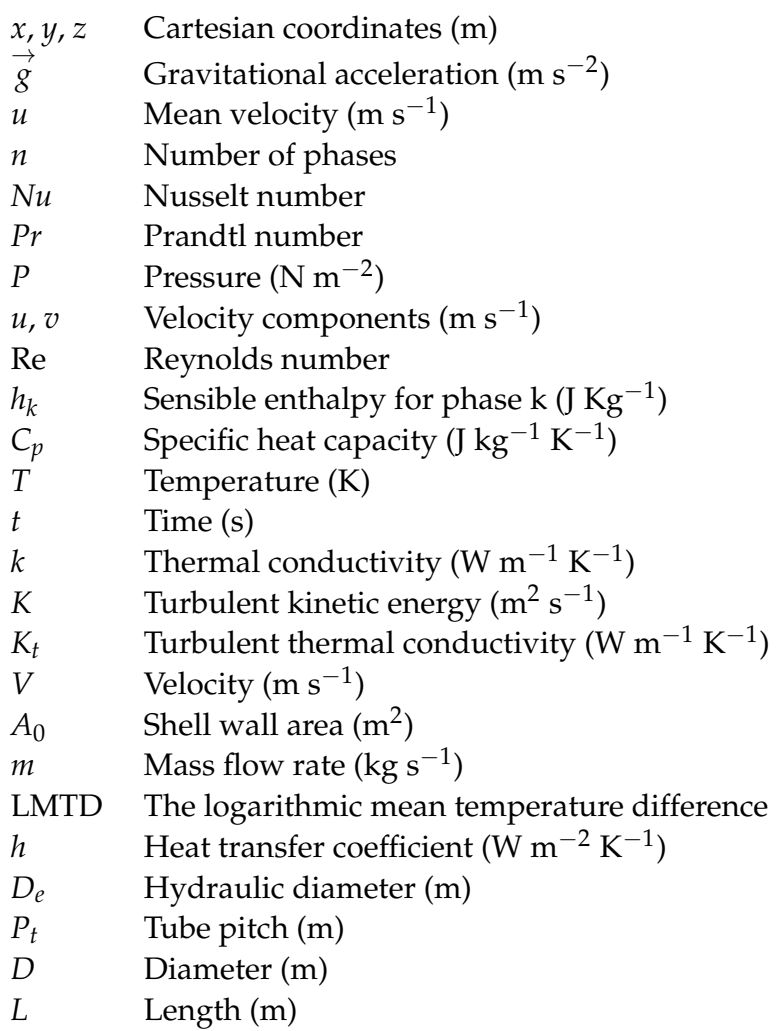




\section{Greek Symbols}

$\begin{array}{ll}\rho & \text { Density }\left(\mathrm{kg} \mathrm{m}^{-3}\right) \\ \varepsilon & \text { Dissipation rate of Turbulent Kinetic Energy }\left(\mathrm{m}^{2} \mathrm{~s}^{-3}\right) \\ \mu & \text { Dynamic Viscosity (Pa s) } \\ v & \text { Kinematic Viscosity }\left(\mathrm{m}^{2} \mathrm{~s}^{-1}\right) \\ v_{t, m} & \text { Turbulent Eddy Viscosity }\left(\mathrm{m}^{2} \mathrm{~s}^{-1}\right) \\ \phi & \text { Volume Fraction of Nanoparticles }\end{array}$

\section{Subscripts}

$\begin{array}{ll}\text { eff } & \text { Effective } \\ Z & \text { Indices } \\ m & \text { Mixture } \\ t & \text { Turbulent } \\ w & \text { Wall } \\ \text { in } & \text { Inlet } \\ \text { out } & \text { Outlet } \\ s & \text { Shell } \\ \text { min } & \text { Minimum } \\ \text { max } & \text { Maximum }\end{array}$

\section{References}

1. Sarafraz, M.M.; Tian, Z.; Tlili, I.; Kazi, S.; Goodarzi, M. Thermal evaluation of a heat pipe working with n-pentane-acetone and n-pentane-methanol binary mixtures. J. Therm. Anal. Calorim. 2020, 139, 2435-2445. [CrossRef]

2. Benabderrahmane, Y.; Pain, J.-P. Thermal behaviour of a solid/liquid mixture in an ohmic heating sterilizer-slip phase model. Chem. Eng. Sci. 2000, 55, 1371-1384. [CrossRef]

3. Chou, T.S.; Worley, F.L., Jr.; Luss, D. Local particle-liquid mass transfer fluctuations in mixed-phase cocurrent downflow through a fixed bed in the pulsing regime. Ind. Eng. Chem. Fundam. 1979, 18, 279-283. [CrossRef]

4. Safaei, M.R.; Safdari Shadloo, M.; Goodarzi, M.S.; Hadjadj, A.; Goshayeshi, H.R.; Afrand, M.; Kazi, S. A survey on experimental and numerical studies of convection heat transfer of nanofluids inside closed conduits. Adv. Mech. Eng. 2016, 8, 1687814016673569. [CrossRef]

5. Ahmadi, M.H.; Mohseni-Gharyehsafa, B.; Ghazvini, M.; Goodarzi, M.; Jilte, R.D.; Kumar, R. Comparing various machine learning approaches in modeling the dynamic viscosity of $\mathrm{CuO} /$ water nanofluid. J. Therm. Anal. Calorim. 2020, 139, 2585-2599. [CrossRef]

6. Choi, S.U.; Eastman, J.A. Enhancing thermal conductivity of fluids with nanoparticles. In Proceedings of the 1995 International Mechanical Engineering Congress and Exhibition, San Francisco, CA, USA, 12-17 November 1995; Argonne National Lab.: Lemont, IL, USA, 1995.

7. Hosseini, S.M.; Safaei, M.R.; Estellé, P.; Jafarnia, S.H. Heat transfer of water-based carbon nanotube nanofluids in the shell and tube cooling heat exchangers of the gasoline product of the residue fluid catalytic cracking unit. J. Therm. Anal. Calorim. 2020, 140, 351-362. [CrossRef]

8. Bahmani, M.H.; Sheikhzadeh, G.; Zarringhalam, M.; Akbari, O.A.; Alrashed, A.A.; Shabani, G.A.S.; Goodarzi, M. Investigation of turbulent heat transfer and nanofluid flow in a double pipe heat exchanger. Adv. Powder Technol. 2018, 29, 273-282. [CrossRef]

9. Sajid, M.U.; Ali, H.M. Thermal conductivity of hybrid nanofluids: A critical review. Int. J. Heat Mass Transf. 2018, 126, 211-234. [CrossRef]

10. Sajid, M.U.; Ali, H.M. Recent advances in application of nanofluids in heat transfer devices: A critical review. Renew. Sustain. Energy Rev. 2019, 103, 556-592. [CrossRef]

11. Olabi, A.; Elsaid, K.; Sayed, E.T.; Mahmoud, M.S.; Wilberforce, T.; Hassiba, R.J.; Abdelkareem, M.A. Application of Nanofluids for Enhanced Waste Heat Recovery: A Review. Nano Energy 2021, 84, 105871. [CrossRef]

12. Goodarzi, M.; Javid, S.; Sajadifar, A.; Nojoomizadeh, M.; Motaharipour, S.H.; Bach, Q.-V.; Karimipour, A. Slip velocity and temperature jump of a non-Newtonian nanofluid, aqueous solution of carboxy-methyl cellulose/aluminum oxide nanoparticles, through a microtube. Int. J. Numer. Methods Heat Fluid Flow 2019, 29, 1606-1628. [CrossRef]

13. Ambreen, T.; Kim, M.-H. Effects of variable particle sizes on hydrothermal characteristics of nanofluids in a microchannel. Int. J. Heat Mass Transf. 2018, 120, 490-498. [CrossRef]

14. Abdollahi-Moghaddam, M.; Motahari, K.; Rezaei, A. Performance characteristics of low concentrations of CuO/water nanofluids flowing through horizontal tube for energy efficiency purposes; an experimental study and ANN modeling. J. Mol. Liq. 2018, 271, 342-352. [CrossRef]

15. Alrashed, A.A.; Akbari, O.A.; Heydari, A.; Toghraie, D.; Zarringhalam, M.; Shabani, G.A.S.; Seifi, A.R.; Goodarzi, M. The numerical modeling of water/FMWCNT nanofluid flow and heat transfer in a backward-facing contracting channel. Phys. $B$ Condens. Matter 2018, 537, 176-183. [CrossRef] 
16. Togun, H.; Ahmadi, G.; Abdulrazzaq, T.; Shkarah, A.J.; Kazi, S.N.; Badarudin, A.; Safaei, M. Thermal performance of nanofluid in ducts with double forward-facing steps. J. Taiwan Inst. Chem. Eng. 2015, 47, 28-42. [CrossRef]

17. Ho, C.J.; Cheng, C.-Y.; Yang, T.-F.; Rashidi, S.; Yan, W.-M. Experimental study on cooling performance of nanofluid flow in a horizontal circular tube. Int. J. Heat Mass Transf. 2021, 169, 120961. [CrossRef]

18. Hamedani, F.A.; Ajarostaghi, S.S.M.; Hosseini, S.A. Numerical evaluation of the effect of geometrical and operational parameters on thermal performance of nanofluid flow in convergent-divergent tube. J. Therm. Anal. Calorim. 2020, 140, 1483-1505. [CrossRef]

19. Chaurasia, S.R.; Sarviya, R.M. Thermal performance analysis of $\mathrm{CuO} /$ water nanofluid flow in a pipe with single and double strip helical screw tape. Appl. Therm. Eng. 2020, 166, 114631. [CrossRef]

20. Hussain, M.I.; Kim, J.-H.; Kim, J.-T. Nanofluid-Powered Dual-Fluid Photovoltaic/Thermal (PV/T) System: Comparative Numerical Study. Energies 2019, 12, 775. [CrossRef]

21. Bahiraei, M.; Jamshidmofid, M.; Goodarzi, M. Efficacy of a hybrid nanofluid in a new microchannel heat sink equipped with both secondary channels and ribs. J. Mol. Liq. 2019, 273, 88-98. [CrossRef]

22. Bagherzadeh, S.A.; Jalali, E.; Sarafraz, M.M.; Akbari, O.A.; Karimipour, A.; Goodarzi, M.; Bach, Q.-V. Effects of magnetic field on micro cross jet injection of dispersed nanoparticles in a microchannel. Int. J. Numer. Methods Heat Fluid Flow 2019, 30, $2683-2704$. [CrossRef]

23. Ting, T.W.; Hung, Y.M.; Guo, N. Viscous dissipative nanofluid convection in asymmetrically heated porous microchannels with solid-phase heat generation. Int. Commun. Heat Mass Transf. 2015, 68, 236-247. [CrossRef]

24. Gheynani, A.R.; Akbari, O.A.; Zarringhalam, M.; Shabani, G.A.S.; Alnaqi, A.A.; Goodarzi, M.; Toghraie, D. Investigating the effect of nanoparticles diameter on turbulent flow and heat transfer properties of non-Newtonian carboxymethyl cellulose/CuO fluid in a microtube. Int. J. Numer. Methods Heat Fluid Flow 2019, 29, 1699-1723. [CrossRef]

25. Abou Elmaaty, T.M.; Kabeel, A.; Mahgoub, M. Corrugated plate heat exchanger review. Renew. Sustain. Energy Rev. 2017, 70, 852-860. [CrossRef]

26. Rahimi, A.; Amiri, A.; Kasaeipoor, A.; Malekshah, E.H. Heat transfer enhancement using $\mathrm{Al}_{2} \mathrm{O}_{3}$-EG/W(60/40vol\%) in multiplepipe heat exchanger. J. Mol. Liq. 2018, 261, 319-336. [CrossRef]

27. Chandrasekar, K.; Murali, B.B.; Prabhakaran, T.; Jayachandran, S. CFD analysis of shell and tube heat exchanger. Adv. Nat. Appl. Sci. 2016, 10, 72-79.

28. Gay, B.; Jenkins, J.; Mackley, N. Shell-side heat transfer in double-segmentally baffled cylindrical shell-and-tube exchangers. Lett. Heat Mass Transf. 1982, 9, 39-47. [CrossRef]

29. Biçer, N.; Engin, T.; Yaşar, H.; Büyükkaya, E.; Aydın, A. Design optimization of a shell-and-tube heat exchanger with novel three-zonal baffle by using CFD and taguchi method. Int. J. Therm. Sci. 2020, 155, 106417. [CrossRef]

30. Abbasi, H.R.; Sedeh, E.S.; Pourrahmani, H.; Mohammadi, M.H. Shape optimization of segmental porous baffles for enhanced thermo-hydraulic performance of shell-and-tube heat exchanger. Appl. Therm. Eng. 2020, 180, 115835. [CrossRef]

31. Petinrin, M.O.; Dare, A.A. Numerical and Experimental Investigation on Performance of Convex-Cut Baffles in Shell-and-Tube Heat Exchanger. J. Eng. Res. Rep. 2020, 8-26. [CrossRef]

32. Cucumo, M.A.; Ferraro, V.; Kaliakatsos, D.; Mele, M.; Galloro, A.; Schimio, R.; Le Pera, G. Computational Fluid Dynamics Analysis of a Heat Exchanger Provided with Helical Baffles. Heat Transf. Eng. 2020, 41, 1026-1039. [CrossRef]

33. Goodarzi, M.; Safaei, M.; Vafai, K.; Ahmadi, G.; Dahari, M.; Kazi, S.; Jomhari, N. Investigation of nanofluid mixed convection in a shallow cavity using a two-phase mixture model. Int. J. Therm. Sci. 2014, 75, 204-220. [CrossRef]

34. Yarmand, H.; Gharehkhani, S.; Ahmadi, G.; Shirazi, S.F.S.; Baradaran, S.; Montazer, E.; Zubir, M.N.M.; Alehashem, M.S.; Kazi, S.; Dahari, M. Graphene nanoplatelets-silver hybrid nanofluids for enhanced heat transfer. Energy Convers. Manag. 2015, 100, 419-428. [CrossRef]

35. Patankar, S. Numerical Heat Transfer and Fluid Flow; Taylor \& Francis: New York, NY, USA, 2018.

36. Bahiraei, M.; Heshmatian, S.; Goodarzi, M.; Moayedi, H. CFD analysis of employing a novel ecofriendly nanofluid in a miniature pin fin heat sink for cooling of electronic components: Effect of different configurations. Adv. Powder Technol. 2019, 30, $2503-2516$. [CrossRef]

37. Yousefzadeh, S.; Rajabi, H.; Ghajari, N.; Sarafraz, M.M.; Akbari, O.A.; Goodarzi, M. Numerical investigation of mixed convection heat transfer behavior of nanofluid in a cavity with different heat transfer areas. J. Therm. Anal. Calorim. 2019, 140, $2779-2803$. [CrossRef]

38. Arasteh, H.; Mashayekhi, R.; Goodarzi, M.; Motaharpour, S.H.; Dahari, M.; Toghraie, D. Heat and fluid flow analysis of metal foam embedded in a double-layered sinusoidal heat sink under local thermal non-equilibrium condition using nanofluid. $J$. Therm. Anal. Calorim. 2019, 138, 1461-1476. [CrossRef]

39. Bahmani, M.H.; Akbari, O.A.; Zarringhalam, M.; Shabani, G.A.S.; Goodarzi, M. Forced convection in a double tube heat exchanger using nanofluids with constant and variable thermophysical properties. Int. J. Numer. Methods Heat Fluid Flow 2019, 30, 3247-3265. [CrossRef]

40. Yin, M.; Shi, F.; Xu, Z. Renormalization group based $\kappa-\varepsilon$ turbulence model for flows in a duct with strong curvature. Int. J. Eng. Sci. 1996, 34, 243-248. [CrossRef]

41. Kaya, F.; Karagoz, I. Performance analysis of numerical schemes in highly swirling turbulent flows in cyclones. Curr. Sci. 2008, 94, 1273-1278. 
42. Mellal, M.; Benzeguir, R.; Sahel, D.; Ameur, H. Hydro-thermal shell-side performance evaluation of a shell and tube heat exchanger under different baffle arrangement and orientation. Int. J. Therm. Sci. 2017, 121, 138-149. [CrossRef]

43. Sundar, L.S.; Singh, M.K.; Sousa, A.C. Enhanced heat transfer and friction factor of MWCNT-Fe3O4/water hybrid nanofluids. Int. Commun. Heat Mass Transf. 2014, 52, 73-83. [CrossRef] 